\title{
El cálculo de las necesidades de gasto regionales: notas para la discusión ${ }^{*}$
}

\author{
Angel de la Fuente \\ FEDEA e Instituto de Análisis Económico (CSIC)
}

Octubre de 2015

\section{Resumen}

Con el ánimo de estimular la discusión informada de cara a la próxima reforma del sistema de financiación regional, en este trabajo se repasa el procedimiento de cálculo de las necesidades de gasto que se utiliza en el mismo y se discuten posibles mejoras de la metodología actual. Los cambios contemplados incluyen ligar las ponderaciones de las variables de reparto al patrón observado de gasto autonómico, la inclusión de nuevos indicadores de necesidades no recogidos en el modelo actual, el desdoblamiento de otros ya existentes y la introducción de correcciones por niveles regionales de precios y de renta. Tras descartar algunas de estas posibilidades o condicionar su adopción a la realización de trabajos previos, el estudio concluye con una propuesta provisional para la modificación inmediata de la actual fórmula de reparto y una cuantificación de sus implicaciones para las necesidades de gasto por habitante de las distintas comunidades autónomas elaborada con datos de 2013.

Palabras clave: necesidades de gasto, financiación autonómica

Clasificación JEL: H70

\footnotetext{
* Este trabajo forma parte de un proyecto financiado en parte por la Fundación SEPI. Agradezco también la financiación del Ministerio de Ciencia e Innovación a través del proyecto ECO2014-59196-P así como los comentarios y sugerencias de Julio López Laborda.
} 


\section{Resumen}

Las necesidades de gasto de las comunidades autónomas - que no deben confundirse con su financiación real - son una pieza importante de los mecanismos redistributivos o de nivelación del sistema de financiación regional. Las necesidades de gasto describen una pauta igualitaria de reparto que aseguraría que todas las comunidades pueden ofrecer prestaciones similares. Se trataría por tanto del objetivo ideal de la nivelación, al que generalmente no se llega en la práctica pero que sí tiene un cierto impacto sobre los resultados del sistema.

Con el ánimo de estimular la discusión informada de cara a la próxima reforma del sistema de financiación autonómica, en el presente trabajo se repasa el procedimiento de cálculo de las necesidades de gasto (o poblaciones ajustadas) regionales que se utiliza en España y se discuten posibles mejoras de la metodología actual, cuantificando sus implicaciones y valorando la deseabilidad de su adopción. El trabajo concluye que convendría adoptar de forma inmediata las siguientes modificaciones:

1) Ligar las ponderaciones de las variables incluidas en la fórmula de necesidades de gasto al peso observado en el gasto regional de los correspondientes grupos de competencias. A estos efectos, se deduciría de los gastos observados la parte que se financia con transferencias condicionadas específicas, como los Fondos europeos, y no a través del sistema general de financiación.

2) Recuperar una pequeña partida de costes fijos, que ya existía en versiones anteriores del modelo de financiación. Estos recursos se repartirían a partes iguales entre todas las comunidades autónomas con el fin de ayudar a sufragar los costes fijos ligados a las instituciones de autogobierno y a otros servicios autonómicos, que son especialmente gravosos en el caso de las comunidades más pequeñas.

3) Desdoblar el indicador de necesidades de gasto educativo, reemplazando la población de 0 a 16 años por la combinación de la población 3-18 y el alumnado de las universidades públicas, con ponderaciones que reflejen el peso relativo del gasto educativo universitario y no universitario.

4) Desdoblar el indicador de necesidades de gasto en protección social, incluyendo en la fórmula de reparto, además de la población mayor de 64 años, la población en riesgo de pobreza o exclusión social

También se concluye que sería deseable introducir correcciones por los niveles regionales de precios y de renta, así como, posiblemente, incorporar algún indicador del stock o el flujo de población inmigrante. Para ello, sin embargo, sería necesario realizar algunos trabajos previos de carácter técnico, incluyendo la elaboración de un índice fiable de precios relativos regionales y un análisis detallado de los costes ligados a la inmigración. 


\section{Introducción}

En la mayor parte de los países descentralizados el sistema de financiación regional incluye una serie de mecanismos de nivelación que complementan la financiación de los territorios con menores recursos tributarios propios con el fin de que estos puedan ofrecer servicios al menos aproximadamente similares a los del resto del país. Un componente importante de tales mecanismos redistributivos es una fórmula de reparto o de necesidades de gasto que nos da una estimación de la financiación que idealmente debería recibir cada territorio para conseguir la plena igualdad entre todos ellos, posiblemente teniendo en cuenta los costes relativos de provisión de los servicios relevantes en cada uno. El objetivo del sistema de nivelación es acercarnos, al menos parcialmente, a esta pauta ideal de reparto mediante transferencias que fluyen horizontalmente, de las regiones más ricas a las más pobres, o verticalmente, desde el Gobierno Central o la Federación hacia los estados o regiones.

El procedimiento que se utiliza en España para cuantificar las necesidades regionales de gasto ocupa una posición intermedia en cuanto a su grado de complejidad en relación con los métodos utilizados con el mismo fin en otros países descentralizados. En un extremo tenemos países como Canadá, en los que el objetivo del sistema de nivelación se formula en términos de recursos por habitante, lo que es equivalente a utilizar la población como único criterio para la fijación de las necesidades de gasto. En el extremo contrario se situaría Australia, donde existe un organismo independiente que se encarga de realizar estimaciones muy detalladas de los costes medios de los distintos servicios públicos en cada estado.

Ambos enfoques extremos presentan problemas evidentes. Por un lado, resulta claro que la nivelación de la financiación por habitante no garantiza la igualdad en la capacidad de prestación de servicios cuando los territorios que conforman un país presentan diferencias importantes en su estructura demográfica que afectan a la demanda de ciertos servicios o características geográficas muy diferentes que pueden incidir sobre los costes unitarios de provisión de los mismos. Por otro lado, el intento de afinar demasiado en el cálculo de los costes requiere una información muy detallada y costosa, reduce la transparencia del sistema y exige inevitablemente hipótesis de trabajo discutibles que hacen que los resultados sean siempre cuestionables.

En este contexto, la apuesta española por un procedimiento intermedio que intenta evitar los inconvenientes de ambos extremos parece acertada en principio. Aún así, en este trabajo se argumenta que en nuestro país existe todavía un margen apreciable para afinar los cálculos de necesidades de gasto utilizando información fácilmente disponible y sin pérdida alguna de transparencia. El artículo se estructura como sigue. En la sección 2 se repasa brevemente el

\footnotetext{
1 Sobre el funcionamiento de los mecanismos de nivelación en estos países y sus posibles problemas, véanse López y Rodrigo (2000) y de la Fuente y Gundín (2008a).
} 
procedimiento de cálculo de las necesidades de gasto que se aplica actualmente en España y se describen sus resultados, que pueden resumirse en un intuitivo indicador de necesidades de gasto por habitante (ngph). Con el ánimo de estimular la discusión informada sobre el tema de cara a la próxima reforma del sistema, en el resto del trabajo se discuten posibles mejoras de la metodología actual y se exploran sus implicaciones para el cálculo de las ngph. Los cambios contemplados en la fórmula de reparto incluyen ligar las ponderaciones de las variables de reparto al patrón observado de gasto autonómico, la inclusión de nuevos indicadores de necesidades no recogidos en el modelo actual, el desdoblamiento de otros ya existentes y la introducción de correcciones por niveles regionales de precios y de renta. Tras descartar algunas de estas posibilidades o condicionar su adopción a la realización de trabajos previos, el estudio concluye con una propuesta provisional para la modificación inmediata de la actual fórmula de reparto y con una cuantificación de sus implicaciones para las necesidades de gasto por habitante de las distintas comunidades autónomas elaborada con datos de 2013.

\section{Las necesidades de gasto y la población ajustada en el sistema actual}

En el sistema español de financiación regional las necesidades de gasto se calculan utilizando una fórmula relativamente sencilla en la que entran los factores demográficos y geográficos con una mayor incidencia sobre la demanda de los principales servicios públicos gestionados por las autonomías y sobre sus costes unitarios de provisión. El sistema no pretende cuantificar lo que costaría en términos absolutos prestar todos los servicios de titularidad autonómica al nivel que sería óptimo en algún sentido, pero sí intenta ofrecer una pauta de reparto igualitario que asegure que las necesidades de todas las comunidades quedan cubiertas en aproximadamente la misma proporción. La función de los distintos mecanismos de nivelación incluidos en el sistema es la de acercar la financiación a esta pauta ideal, o lo que viene a ser lo mismo, la de reducir las diferencias de recursos que se observan en primera instancia entre territorios ricos y pobres.

\section{Cuadro 1: Variables que entran en la fórmula actual de necesidades de gasto y sus ponderaciones}

\begin{tabular}{llr}
\hline Competencias: & Indicador: & ponderación \\
- sanidad & - población protegida equivalente & $38 \%$ \\
- servicios generales & - población empadronada a 1 de enero & $30 \%$ \\
- educación & - población en edad escolar (0-16) & $20,5 \%$ \\
- servicios sociales & - población 65+ & $8,5 \%$ \\
Correcciones: & - superficie & $1,8 \%$ \\
& - dispersión de la población (entidades singulares) & $0,6 \%$ \\
& - insularidad & $0,6 \%$ \\
\hline
\end{tabular}

El Cuadro 1 muestra las variables de reparto o indicadores de necesidad del sistema actual y sus ponderaciones, esto es, la fracción de los recursos disponibles que habría que distribuir en proporción a cada una de estas variables para llegar al reparto que serviría como norma de 
equidad para el sistema. ${ }^{2}$ Así por ejemplo, un $30 \%$ de los fondos disponibles se repartirían en proporción a la población regional y un 1,8\% en proporción a la superficie, mientras que un $0,6 \%$ se reservaría para las dos comunidades insulares.

La actual ley de financiación regional (BOE, 2009, arts. 9.b y 19.3) define con precisión las distintas variables de reparto. La población corresponde a la población empadronada a 1 de enero de cada año, mientras que el indicador de dispersión es el número de núcleos de población (entidades singulares) existente en cada región en el año corriente. La partida asignada a la insularidad se reparte entre Baleares y Canarias en proporción a la distancia, ponderada por tramos, entre sus respectivas capitales y las costas peninsulares, lo que implica asignar a Canarias un 79,9\% de su importe total. La población protegida equivalente a efectos de gasto sanitario se calcula ponderando la población protegida por el Sistema Nacional de Salud, dividida en siete tramos de edad, en proporción al nivel relativo de gasto sanitario per cápita de cada tramo, siguiendo la metodología desarrollada por el Grupo de Trabajo sobre gasto sanitario creado por la Conferencia de Presidentes (GTS, 2007).

Las variables que entran en la fórmula de necesidades de gasto pueden dividirse en dos grupos. Por un lado tenemos cuatro indicadores de población o población ponderada que de alguna manera miden la demanda de las principales categorías de servicios públicos a través del número de usuarios reales o potenciales de los mismos, posiblemente ponderados por intensidad de uso. Informalmente, por tanto, podemos hablar de cuatro tramos de financiación que, tal como se indica en el Cuadro 1, estarían ligados a la sanidad, la educación, los servicios sociales y el resto de los servicios autonómicos a los que por abreviar podríamos denominar de carácter general. ${ }^{3}$ Aquí entrarían competencias tan dispares como cultura, vivienda, empleo, infraestructuras, regulación y ayudas a los sectores económicos y administración y servicios generales. Por otra parte, el modelo incluye también tres variables de carácter geográfico (dispersión de la población, superficie e insularidad) para las que se reserva un $3 \%$ de los recursos disponibles con el fin de introducir correcciones en los costes medios por usuario de los distintos territorios en función de sus características.

\section{La población ajustada}

La fórmula de reparto del sistema se utiliza también para calcular la población ajustada de cada comunidad autónoma - una variable que recoge las necesidades de gasto regionales de una forma que resulta particularmente conveniente. En este caso, lo que se reparte con los criterios resumidos en el Cuadro 1 no son los recursos económicos del sistema sino la población total del conjunto de las comunidades de régimen común. Lo que se consigue con esta operación es ponderar las poblaciones regionales por un factor que recoge el coste diferencial por habitante

\footnotetext{
2 Existe una cierta controversia sobre si la fórmula resumida en el Cuadro 1 pretende cuantificar las necesidades totales de gasto de las comunidades autónomas, tal como aquí se supone, o sólo aquellas ligadas a la provisión de los servicios considerados fundamentales (educación, sanidad y servicios sociales). Sobre este tema, véase la sección 3.2 de de la Fuente (2010).

${ }^{3}$ Una aclaración seguramente innecesaria: estos cuatro "tramos" de financiación son, a mi entender, una construcción útil para el cálculo de las necesidades de gasto pero no existen oficialmente como tales y desde luego ni restringen en modo alguno la autonomía de los gobiernos regionales para decidir la composición de su gasto ni estoy proponiendo que lo hagan.
} 
de prestar en cada región los principales servicios autonómicos a un nivel de calidad uniforme para todas ellas. De esta forma se introduce una corrección por el hecho de que los costes por habitante de los servicios públicos serán mayores en las regiones más envejecidas o más extensas, por citar sólo dos de los factores relevantes.

Si dividimos la financiación de cada región por su población ajustada se obtiene un indicador de financiación por unidad de necesidad. Este indicador nos proporciona un criterio operativo de equidad: si lo que buscamos es que todos los ciudadanos, con independencia de su región de residencia, puedan acceder en condiciones de igualdad a los servicios públicos que gestionan las autonomías, lo que tenemos que hacer es igualar la financiación por habitante ajustado de todas las comunidades autónomas.

Gráfico 1: Necesidades de gasto por habitante (ngph) bajo el sistema actual, 2013

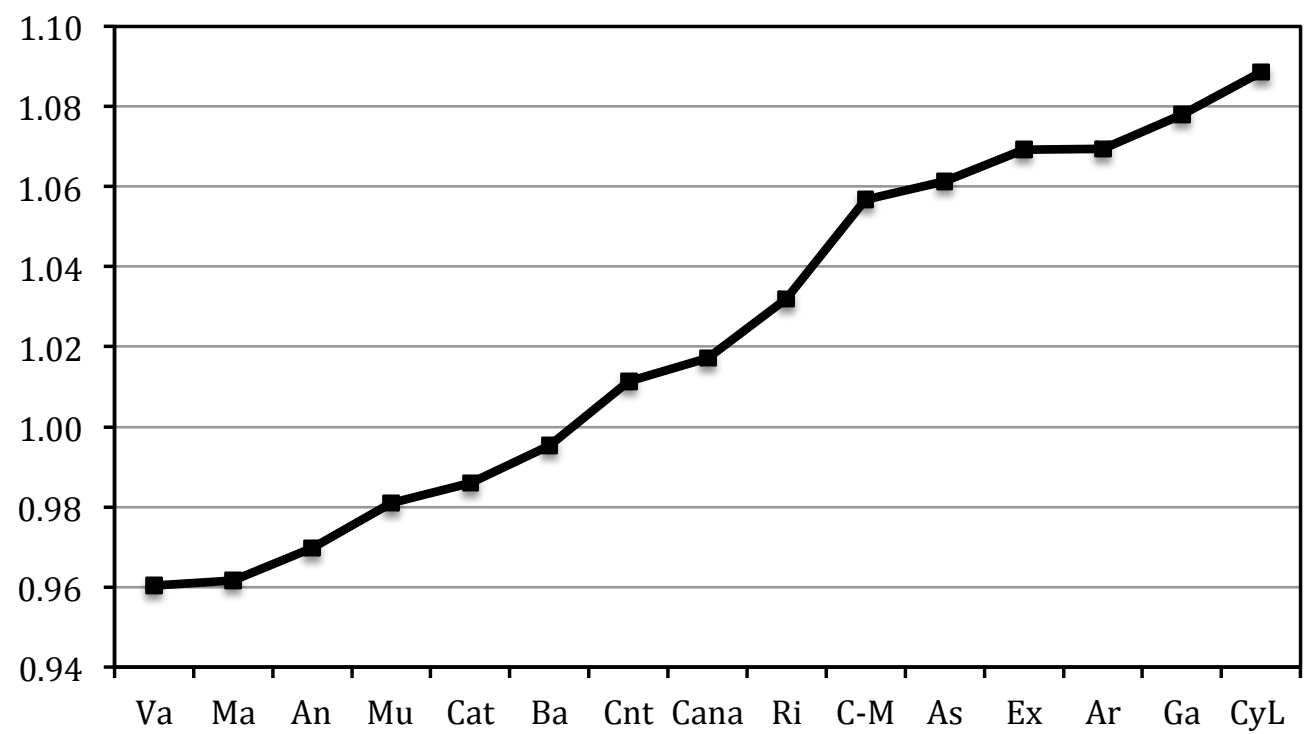

De igual forma, dividiendo la población ajustada por la población real de cada territorio se obtiene un indicador de necesidades de gasto por habitante (ngph) que resume la estimación que hace el sistema del coste medio por habitante de los servicios de titularidad autonómica en cada territorio. El Gráfico 1 muestra el valor de este indicador correspondiente a 2013, calculado con la fórmula del sistema actualmente vigente. Existe un abanico de unos 13 puntos porcentuales entre los extremos de la distribución. Las regiones con mayores necesidades de gasto per cápita son aquellas que cuentan con poblaciones envejecidas, patrones dispersos de poblamiento y bajas densidades de población. En el extremo opuesto encontramos regiones con poblaciones relativamente jóvenes, concentradas en un número reducido de grandes núcleos urbanos, y con densidades elevadas de población.

\section{La contribución de las distintas variables de reparto a las necesidades de gasto}

La fórmula de reparto del sistema de financiación regional no está escrita de una forma que permita valorar directamente sus implicaciones. No resulta evidente, por ejemplo, si la reserva de un porcentaje dado del volumen total de recursos para las comunidades insulares supone o 
no una compensación razonable por los sobrecostes que éstas soportan en la provisión de ciertos servicios públicos. Para mitigar este problema, en este apartado extraeré de la fórmula de necesidades de gasto del sistema las primas porcentuales en costes por habitante generadas por cada una de las variables incluidas en la misma dadas sus ponderaciones actuales.

El Cuadro 2 muestra la aportación de cada variable de reparto al indicador de necesidades de gasto por habitante medido en términos relativos, esto es, en desviaciones sobre su promedio, que se normaliza a 100. La última columna (total) nos da las necesidades relativas de gasto por habitante de cada región (el diferencial en puntos porcentuales con el promedio) y se obtiene sumando el resto de las columnas. Las dos últimas filas del cuadro muestran la desviación estándar (desv. est.) de los distintos componentes de la financiación relativa y su rango, esto es, un indicador de dispersión y la diferencia entre el valor máximo y el mínimo dentro de cada columna. Estos dos indicadores nos dan una idea de la contribución de las distintas variables de reparto a la desigualdad observada en términos de necesidades de gasto por habitante. Los criterios que generan mayores disparidades son el nivel de envejecimiento de la población (recogido por la población protegida equivalente) y la insularidad, con un rango de más 10 puntos, seguidos de la población en edad escolar, la superficie, la población mayor de 65 años y la dispersión.

\section{Cuadro 2: Componentes de las necesidades relativas de gasto por habitante (contribución de cada variable de reparto a la desviación porcentual de las necesidades de gasto por habitante sobre el promedio)}

\begin{tabular}{|c|c|c|c|c|c|c|c|c|}
\hline & $\begin{array}{c}\text { población } \\
\text { total }\end{array}$ & $\begin{array}{l}\text { super- } \\
\text { ficie }\end{array}$ & $\begin{array}{l}\text { disper- } \\
\text { sionn }\end{array}$ & $\begin{array}{c}\text { insulari- } \\
\text { dad }\end{array}$ & $\begin{array}{c}\text { población } \\
\text { protegida } \\
\text { equival }\end{array}$ & $\begin{array}{l}\text { pob. } \\
65+\end{array}$ & $\begin{array}{c}\text { pob. } 0 \text { a } \\
16\end{array}$ & $\begin{array}{c}\text { total }= \\
\text { nec rel de } \\
\text { gasto por } \\
\text { habitante }\end{array}$ \\
\hline Cataluña & 0,0 & $-1,1$ & $-0,4$ & $-0,6$ & 0,0 & $-0,1$ & 0,8 & $-1,4$ \\
\hline Galicia & 0,0 & $-0,1$ & 4,3 & $-0,6$ & 5,8 & 2,7 & $-4,3$ & 7,8 \\
\hline Andalucía & 0,0 & $-0,1$ & $-0,5$ & $-0,6$ & $-2,8$ & $-0,9$ & 1,9 & $-3,0$ \\
\hline Asturias & 0,0 & $-0,2$ & 2,3 & $-0,6$ & 7,6 & 2,7 & $-5,6$ & 6,1 \\
\hline Cantabria & 0,0 & $-0,3$ & 0,1 & $-0,6$ & 3,3 & 0,8 & $-2,2$ & 1,1 \\
\hline La Rioja & 0,0 & 0,7 & $-0,2$ & $-0,6$ & 2,9 & 0,7 & $-0,2$ & 3,2 \\
\hline Murcia & 0,0 & $-0,5$ & $-0,3$ & $-0,6$ & $-2,5$ & $-1,5$ & 3,6 & $-1,9$ \\
\hline Valencia & 0,0 & $-1,1$ & $-0,5$ & $-0,6$ & $-1,9$ & 0,2 & 0,0 & $-4,0$ \\
\hline Aragón & 0,0 & 4,0 & $-0,1$ & $-0,6$ & 3,9 & 1,3 & $-1,5$ & 6,9 \\
\hline C.- Mancha & 0,0 & 4,4 & $-0,2$ & $-0,6$ & 1,3 & 0,1 & 0,8 & 5,7 \\
\hline Canarias & 0,0 & $-1,2$ & $-0,4$ & 9,4 & $-4,1$ & $-1,5$ & $-0,5$ & 1,7 \\
\hline Extremadura & 0,0 & 4,3 & $-0,3$ & $-0,6$ & 3,4 & 0,9 & $-0,7$ & 6,9 \\
\hline Baleares & 0,0 & $-1,1$ & $-0,5$ & 4,2 & $-2,2$ & $-1,4$ & 0,5 & $-0,5$ \\
\hline Madrid & 0,0 & $-1,6$ & $-0,5$ & $-0,6$ & $-0,8$ & $-0,9$ & 0,6 & $-3,8$ \\
\hline Cast. y León & 0,0 & 4,3 & 0,5 & $-0,6$ & 5,8 & 2,8 & $-3,8$ & 8,9 \\
\hline Media CCAA & 0,0 & 0,0 & 0,0 & 0,0 & 0,0 & 0,0 & 0,0 & 0,0 \\
\hline desv est & 0,0 & 2,1 & 1,2 & 2,6 & 3,4 & 1,4 & 2,3 & 4,3 \\
\hline $\max$-min & 0,0 & 6,0 & 4,8 & 10,0 & 11,7 & 4,3 & 9,2 & 12,8 \\
\hline
\end{tabular}

Pese a su limitado peso en el total (un 3\%), las tres variables geográficas generan diferenciales de necesidades de gasto por habitante que llegan a ser muy significativos en las regiones con 
características más extremas. Así, el componente de insularidad de las necesidades de gasto supone una prima muy apreciable para Canarias (a la que se le reconoce un sobrecoste por habitante de 9,4 puntos porcentuales) y en menor medida para Baleares (4,2 puntos). La partida de superficie beneficia especialmente a las comunidades interiores con menor densidad de población, que obtienen primas por habitante superiores a los 4 puntos en las dos Castillas, Aragón y Extremadura. La partida ligada a la dispersión de la población beneficia especialmente a Galicia y Asturias, con primas de 4,3 y 2,3 puntos respectivamente.

También son importantes los efectos de las variables poblacionales. A las regiones más envejecidas se les atribuyen necesidades de gasto por habitante en sanidad y servicios sociales claramente superiores a la media y necesidades de gasto educativo sensiblemente inferiores, mientras que en las comunidades con poblaciones más jóvenes sucede lo contrario. Las primas ligadas a las necesidades de gasto sanitario y educativo muestran un abanico de en torno a los 10 puntos porcentuales cada una, con Asturias, Galicia y Castilla y León en un extremo de la distribución y Andalucía, Murcia y Canarias en el otro.

En términos generales, por tanto, las primas de financiación asociadas a las distintas variables de reparto parecen estar dentro de lo que cabría considerar un rango razonable, lo que no siempre ha sido el caso en anteriores acuerdos de financiación (véase de la Fuente y Vives, 2003). Esto no quiere decir que sus valores sean necesariamente los correctos en algún sentido o al menos no podemos estar seguros de ello porque la evidencia empírica existente sobre el impacto de las variables de interés sobre los costes de provisión de los servicios públicos es muy limitada.

\section{Adecuar los pesos de las variables de reparto al patrón observado de gasto de las Comunidades Autónomas}

Si el objetivo de los mecanismos de nivelación del sistema de financiación regional es el de acercar los recursos de todas las autonomías a los que se necesitarían para financiar una cesta estándar de servicios públicos, parece razonable tomar como referencia la cesta que efectivamente se ofrece en promedio en el conjunto del territorio relevante. Esto es, las ponderaciones en la fórmula de reparto de los indicadores de necesidades de gasto recogidos en el Cuadro 1 deberían reflejar el peso de los correspondientes grupos de competencias en el gasto observado del conjunto de las comunidades autónomas de régimen común -- sin que ello comporte, por supuesto, obligación alguna por parte de éstas de mantener tales ponderaciones en sus propios presupuestos. A estos efectos, sin embargo, convendría deducir de los gastos observados la parte que se financia con transferencias condicionadas, como pueden ser las ayudas de los Fondos Estructurales europeos o la financiación específica del Gobierno Central para competencias singulares, con el fin de aislar aquellas partidas de gasto que han de financiarse con los recursos que proporciona el sistema de financiación general.

En la presente sección, este ejercicio se aborda utilizando datos tomados de las liquidaciones anuales de los presupuestos de las comunidades autónomas que recopila, homogeneiza y 
publica el Ministerio de Hacienda y Administraciones Públicas (MHAP, 2015a). ${ }^{4}$ De aquí se toma el desglose por funciones y capítulos de los gastos y el detalle de ingresos, excluyéndose tanto de los ingresos como de los gastos dos partidas en relación con las cuales algunas comunidades autónomas (pero no todas ellas) actúan como intermediarias: las transferencias del Estado a las corporaciones locales y las subvenciones de la política agraria de la Unión Europea. También se excluyen las operaciones financieras y los intereses (capítulos 8,9 y 3) para quedarnos con un agregado que podríamos llamar de gasto operativo que previsiblemente es el que mejor refleja el coste de los servicios autonómicos. A efectos ilustrativos, el cálculo se realiza con datos de un único año (el ejercicio 2012, que es el más reciente para el que se dispone de datos definitivos). Llegado el caso, seguramente convendría utilizar una media móvil de varios ejercicios.

\section{Cuadro 3: Composición del gasto de las Comunidades Autónomas de Régimen Común en 2012, millones de euros}

\section{Servicios públicos básicos}

a. Justicia

b. Seguridad ciudadana e inst. penitenc.

c. Defensa y política exterior

2. Protección y promoción social

a. Servicios sociales y promoción social

b. Fomento del empleo

c. Vivienda y edificación

d. otros

3. Bienes públicos de carácter preferente

a. Sanidad

b. Educación

c. Cultura

4. Actuaciones de carácter económico

5. Actuaciones de carácter general

total

de lo cual, gasto de personal

peso del gasto de personal

$\begin{array}{rrrr}\begin{array}{l}\text { gasto } \\ \text { bruto }\end{array} & \begin{array}{c}\text { financiación } \\ \text { especifica }\end{array} & \begin{array}{c}\text { gasto } \\ \text { neto }\end{array} & \begin{array}{c}\text { peso } \\ \text { en total }\end{array} \\ \mathbf{4 . 5 3 2} & \mathbf{2 . 5 1 7} & \mathbf{2 . 0 1 5} & \mathbf{1 , 6 9 \%} \\ 2.179 & 1.051 & 1.128 & 0,95 \% \\ 2.195 & 1.466 & 729 & 0,61 \% \\ 158 & & 158 & 0,13 \% \\ \mathbf{1 4 . 9 0 6} & \mathbf{3 . 7 2 9} & \mathbf{1 1 . 1 7 6} & \mathbf{9 , 3 8 \%} \\ 10.393 & 1.719 & 8.674 & 7,28 \% \\ 3.390 & 1.798 & 1.591 & 1,33 \% \\ 947 & 196 & 751 & 0,63 \% \\ 175 & 15 & 160 & 0,13 \% \\ \mathbf{9 2 . 8 0 9} & \mathbf{1 . 2 1 9} & \mathbf{9 1 . 5 9 0} & \mathbf{7 6 , 8 3 \%} \\ 59.511 & 775 & 58.736 & 49,27 \% \\ 32.023 & 273 & 31.750 & 26,63 \% \\ 1.275 & 171 & 1.104 & 0,93 \% \\ \mathbf{1 3 . 5 7 8} & \mathbf{4 . 9 8 9} & \mathbf{8 . 5 8 9} & \mathbf{7 , 2 1 \%} \\ \mathbf{5 . 8 6 7} & \mathbf{2 4} & \mathbf{5 . 8 4 2} & 4,90 \% \\ \mathbf{1 3 1 . 6 9 1} & \mathbf{1 2 . 4 7 8} & \mathbf{1 1 9 . 2 1 3} & \mathbf{1 0 0 , 0 0 \%} \\ & & & \\ & & 46.894 & 39,34 \%\end{array}$

- Fuente: MHAP (2015a, b y c).

- Notas: Se excluyen las operaciones financieras y los intereses (caps. 3,8 y 9). Entre la financiación específica no se incluyen las matrículas universitarias pagadas por las familias porque en la fuente que aquí se utiliza las universidades no se consolidan con las cuentas regionales.

\footnotetext{
${ }^{4}$ Una desventaja de usar datos presupuestarios es que el peso de ciertas partidas de gasto (especialmente la sanidad) podría verse distorsionado en algunos años por el patrón de contabilización de las deudas con proveedores, que no siempre se asignan al ejercicio en el que realmente se produjo el gasto. Para evitar este problema, sería seguramente preferible trabajar con los datos de Contabilidad Nacional que elabora la IGAE (2015). Sin embargo, esta última fuente incluye entre los gastos autonómicos algunas transferencias a otras administraciones públicas que forman parte del sistema de financiación local o autonómico y que, a nuestros efectos, convendría excluir o tratar como parte del proceso de determinación de los ingresos netos regionales, y no ofrece un desglose de los ingresos por transferencias de la UE lo suficientemente detallado para nuestros propósitos. Puesto que no se dispone del detalle necesario para realizar los ajustes oportunos en relación con ambos grupos de transferencias, he optado por trabajar con datos presupuestarios. Si el procedimiento aquí propuesto terminase siendo adoptado, sin embargo, sería conveniente recabar la información necesaria para realizar los cálculos a partir de los datos de Contabilidad Nacional.
} 
La primera columna del Cuadro 3 (gasto bruto) muestra el desglose por funciones del gasto operativo bruto del conjunto de las comunidades autónomas de régimen común en 2012. La segunda columna muestra el importe estimado de la financiación específica de origen estatal y comunitario asignada a las distintas funciones. Substrayendo esta partida del gasto bruto, se obtiene el gasto neto que aparece en la tercera columna. Finalmente, la cuarta columna muestra el peso de cada función en el gasto neto total.

La financiación específica se estima como la suma de tres partidas de transferencias estatales y de la UE. La primera son las transferencias que el Estado realiza a las comunidades autónomas a través del Fondo de Suficiencia para financiar las competencias que han sido asumidas por algunas de ellas pero no por todas, como el personal al servicio de la administración de justicia y la policía autonómica catalana. Esta información se toma del Sistema de Cuentas Públicas Territorializadas de 2012 (MHAP, 2015b). La segunda partida recoge las subvenciones y convenios estatales gestionados por las comunidades autónomas y se toma de MHAP (2015c). Finalmente, se utiliza también el detalle de transferencias de la liquidación de ingresos de las comunidades autónomas de régimen común, que también proporciona MINHAP (2015a), para identificar ciertas transferencias que proporcionan financiación condicionada para inversiones y otros gastos. Aquí se incluyen diversas ayudas de la UE y las transferencias del Fondo de Compensación Interterritorial. El listado detallado de las partidas que he asignado a cada grupo de funciones se recoge en el Anexo. Las dos últimas filas del cuadro muestran el importe total de los gastos de personal de las Comunidades Autónomas y su peso en el gasto neto total. Esta información se utilizará más adelante en conexión con el cálculo de la compensación por diferencias en niveles de precios regionales.

Como cabría esperar, las dos competencias con mayor peso en los presupuestos regionales son la sanidad (que representa el $49 \%$ del gasto neto de financiación específica) y la educación (con algo más del 26\%). En consecuencia, el peso asignado a estas partidas dentro del sistema de financiación actual (un 38\% y un 20,5\% respectivamente) resulta seguramente demasiado bajo, mientras que el peso atribuido a los servicios generales que van ligados al tamaño de la población (actualmente del 30\%) sería excesivo.

Seguidamente se analizan los efectos que tendría adecuar las ponderaciones de los distintos grupos de competencias en la fórmula de necesidades de gasto al patrón observado de gasto autonómico. En el Cuadro 4 se recogen los datos y los cálculos necesarios. La primera fila muestra las ponderaciones actuales de las distintas variables de población incluidas en la fórmula de reparto. La segunda muestra los pesos observados en el gasto autonómico de los grupos de competencias que corresponden a los distintos indicadores. Finalmente, en la tercera fila los pesos recogidos en la fila anterior se reescalan de forma que su suma sea el $97 \%$, dejando, al igual que sucede ahora, un $3 \%$ para los ajustes geográficos contemplados en la fórmula de necesidades de gasto.

Como se observa en la última fila del Cuadro 4, las nuevas ponderaciones propuestas suponen variaciones muy importantes en relación con las actualmente existentes. La partida de servicios generales vería reducido sustancialmente su peso a favor de la educación y la sanidad. Pese a ello, los cambios en el indicador de necesidades totales de gasto por habitante son generalmente 
Cuadro 4: Adecuación de las ponderaciones de los indicadores de necesidades de gasto al patrón observado de gasto regional

\begin{tabular}{|c|c|c|c|c|c|}
\hline Partida: & $\begin{array}{l}\text { servicios } \\
\text { generales }\end{array}$ & sanidad & $\begin{array}{c}\text { servicios } \\
\text { sociales }\end{array}$ & educación & \\
\hline ponderación actual & $\begin{array}{l}\text { población } \\
\text { total } \\
\text { padrón } \\
30 \%\end{array}$ & $\begin{array}{l}\text { población } \\
\text { protegida } \\
\text { equivalente } \\
38 \%\end{array}$ & $\begin{array}{r}\text { pob } 65+ \\
8,50 \%\end{array}$ & $\begin{array}{r}\text { pob } 0 \text { a } 16 \\
20,50 \%\end{array}$ & $\begin{array}{l}\text { total } \\
97,00 \%\end{array}$ \\
\hline peso observado en gasto & $16,82 \%$ & $49,27 \%$ & $7,28 \%$ & $26,63 \%$ & $100,00 \%$ \\
\hline nueva propuesta de ponderación & $16,32 \%$ & $47,79 \%$ & $7,06 \%$ & $25,83 \%$ & $97,00 \%$ \\
\hline variación & $-13,68 \%$ & $+9,79 \%$ & $-1,44 \%$ & $+5,33 \%$ & $0,00 \%$ \\
\hline
\end{tabular}

Gráfico 1: Efectos sobre las necesidades de gasto por habitante en 2013 de actualizar las ponderaciones de las variables de reparto tomando como referencia el patrón observado de gasto.

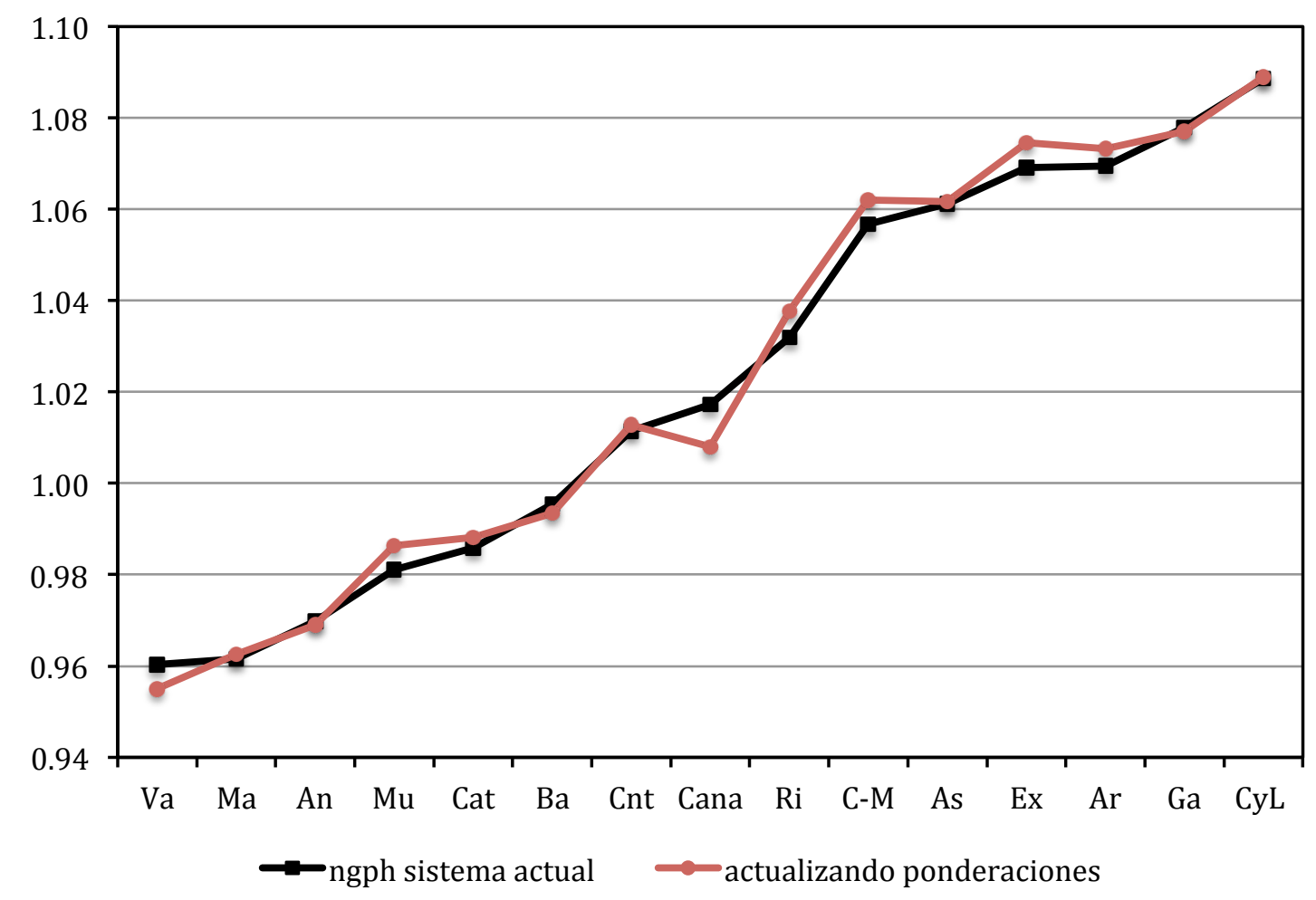

muy menores debido a que las variaciones de las distintas ponderaciones tienden a compensarse entre sí. Las regiones con poblaciones más envejecidas se benefician del mayor peso del indicador de necesidades de gasto sanitario, pero las más jóvenes salen ganando con la mayor ponderación del indicador de necesidades de gasto educativo de una forma que deja a ambos grupos en una situación no muy distinta de la inicial. Tal como se muestra en el Gráfico 1 y el Cuadro 5, los cambios en el indicador de necesidades totales de gasto por habitante (ngph) inducidas por las modificaciones propuestas en las ponderaciones de las variables de reparto se sitúan entre el -0,90\% de Canarias y el $+0,55 \%$ de Rioja. 
Cuadro 5: Efectos sobre las necesidades de gasto por habitante en 2013 de actualizar las ponderaciones de las variables de reparto tomando como referencia el patrón observado de gasto regional

\begin{tabular}{lccc}
\hline & $\begin{array}{c}\text { ngph } \\
\text { sistema } \\
\text { actual }\end{array}$ & $\begin{array}{c}\text { ngph } \\
\text { actualizando } \\
\text { pesos }\end{array}$ & $\%$ var \\
Rioja & 1,032 & 1,038 & $0,55 \%$ \\
Murcia & 0,981 & 0,986 & $0,54 \%$ \\
Extremadura & 1,069 & 1,075 & $0,50 \%$ \\
Cast-Mancha & 1,057 & 1,062 & $0,50 \%$ \\
Aragón & 1,069 & 1,073 & $0,37 \%$ \\
Cataluña & 0,986 & 0,988 & $0,23 \%$ \\
Cantabria & 1,011 & 1,013 & $0,14 \%$ \\
Madrid & 0,962 & 0,963 & $0,10 \%$ \\
Asturias & 1,061 & 1,062 & $0,04 \%$ \\
Cast. y León & 1,089 & 1,089 & $0,02 \%$ \\
Andalucía & 0,970 & 0,969 & $-0,08 \%$ \\
Galicia & 1,078 & 1,077 & $-0,08 \%$ \\
Baleares & 0,995 & 0,993 & $-0,20 \%$ \\
Valencia & 0,960 & 0,955 & $-0,55 \%$ \\
Canarias & 1,017 & 1,008 & $-0,90 \%$ \\
\hline
\end{tabular}

\section{Mejoras en los indicadores de necesidades de gasto}

Además de actualizar las ponderaciones de las variables de reparto, podría ser aconsejable introducir algunas variables nuevas en la fórmula de necesidades de gasto o sustituir algunos de los indicadores actuales por otros que podrían aproximar mejor la demanda de determinados servicios. En esta sección se exploran distintas posibilidades en esta línea. Procediendo como en la sección anterior, el efecto de cada posible cambio se calcula bajo la hipótesis de que ésta es la única desviación sobre la situación existente, tal como se resume en el Cuadro 1. Más adelante, se ofrecerá una estimación del impacto conjunto de aquellos cambios que, a mi entender, habría que incorporar al sistema de forma inmediata.

\subsection{Introducción de una partida de costes fijos}

Una modificación de la fórmula de necesidades de gasto que sería ciertamente aconsejable consistiría en recuperar una pequeña partida de costes fijos. Estos recursos se repartirían a partes iguales entre todas las comunidades autónomas con el fin de ayudar a sufragar los costes fijos ligados a las instituciones de autogobierno y a otros servicios autonómicos, que son especialmente gravosos en el caso de las comunidades más pequeñas. ${ }^{5}$ Esta partida ya existía en anteriores modelos de financiación regional, con un peso ligeramente superior al $1 \%$ en el sistema que comenzó a aplicarse en 2002, y desapareció por razones misteriosas con el Acuerdo de 2009.

\footnotetext{
${ }^{5}$ De la Fuente y Gundín (2009) ofrecen evidencia de la existencia de costes fijos significativos en el caso de la sanidad.
} 
Gráfico 2: Efectos sobre las necesidades de gasto por habitante en 2013 de introducir una partida de costes fijos con una ponderación del 1\%

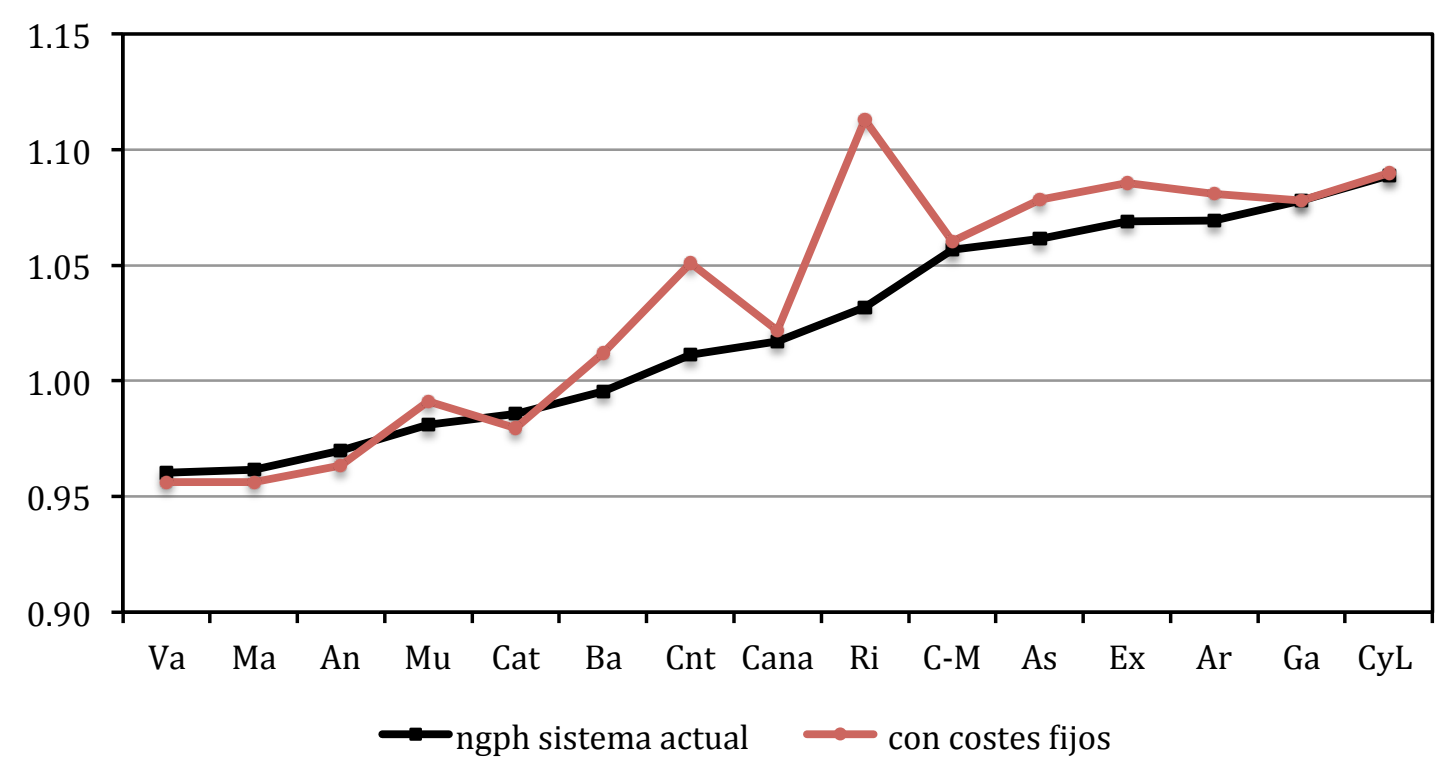

El Gráfico 2 y el Cuadro 6 muestran los efectos sobre las necesidades de gasto por habitante que tendría la recuperación de esta partida con una ponderación del 1\%. Manteniendo constantes los pesos de las variables geográficas, para hacer sitio a los costes fijos hemos ajustado a la baja en la misma proporción las ponderaciones actuales de todos los indicadores de población de forma que su suma sea 0,96 (en vez del 0,97 que alcanzan con el sistema en vigor) y la suma de las ponderaciones de todas las variables de reparto siga siendo igual a la unidad. Como cabría esperar, los efectos son muy reducidos excepto en las comunidades más pequeñas, donde sí suponen una significativa revisión al alza de las necesidades de gasto, que se acerca al 8\% en el caso de la Rioja y al $4 \%$ en el de Cantabria.

Cuadro 6: Efectos sobre las necesidades de gasto por habitante en 2013 de introducir una partida de costes fijos con una ponderación del $1 \%$

\begin{tabular}{lccc}
\hline & $\begin{array}{c}\text { ngph sistema } \\
\text { actual }\end{array}$ & $\begin{array}{c}\text { con costes } \\
\text { fijos }\end{array}$ & var $\%$ \\
Rioja & 1,032 & 1,113 & $+7,85 \%$ \\
Cantabria & 1,011 & 1,051 & $+3,91 \%$ \\
Baleares & 0,995 & 1,012 & $+1,69 \%$ \\
Asturias & 1,061 & 1,078 & $+1,61 \%$ \\
Extremadura & 1,069 & 1,085 & $+1,52 \%$ \\
Aragón & 1,069 & 1,081 & $+1,07 \%$ \\
Murcia & 0,981 & 0,991 & $+1,02 \%$ \\
Canarias & 1,017 & 1,022 & $+0,44 \%$ \\
C.-Mancha & 1,057 & 1,060 & $+0,36 \%$ \\
Cast. y León & 1,089 & 1,090 & $+0,11 \%$ \\
Galicia & 1,078 & 1,078 & $+0,02 \%$ \\
Valencia & 0,960 & 0,956 & $-0,42 \%$ \\
Madrid & 0,962 & 0,956 & $-0,56 \%$ \\
Cataluña & 0,986 & 0,980 & $-0,63 \%$ \\
Andalucía & 0,970 & 0,963 & $-0,65 \%$ \\
& & & \\
\hline
\end{tabular}




\subsection{Modificación del indicador de necesidades de gasto educativo}

El indicador de necesidades de gasto educativo que se utiliza en el sistema actual es la población de 0 a 16 años de edad de acuerdo con el padrón. Esta variable, sin embargo, no parece la más adecuada para esta función porque no coincide ni con el tramo de edad en el que la enseñanza es obligatoria ( 6 a 15$)$ ni con aquel en el que las tasas de escolarización son más elevadas ( 3 a 17 o 18) y porque no recoge en absoluto al alumnado universitario, que seguramente merecería una referencia específica.

A mi entender, sería posible construir un mejor indicador de las necesidades reales de gasto educativo de las comunidades autónomas combinando dos variables. La primera sería la población empadronada con edades comprendidas entre los 3 y los 18 años (INE, 2015a) y la segunda el alumnado universitario matriculado en centros públicos presenciales en cursos de grado (o equivalente) y máster (MECyD, 2015a). La primera variable mantendría la filosofía del actual indicador, recogiendo la población en edad escolar en vez de la escolarizada, aunque afinando el intervalo de edades relevante. La segunda variable, por su parte, recogería las necesidades específicas de gasto universitario. Puesto que las tasas de escolarización a este nivel varían considerablemente entre regiones, gracias en parte a la movilidad estudiantil, y están en cualquier caso lejos de la unidad, parece razonable fijarse directamente en el número de estudiantes antes que en la población total del grupo de edad relevante.

En línea con lo propuesto en la sección 3, las ponderaciones relativas de estos dos indicadores deberían ser proporcionales a los pesos relativos de las enseñanzas universitarias y no universitarias en el gasto autonómico en educación, del que habría que deducir las operaciones financieras y los intereses, las matrículas pagadas por las familias y la financiación específica del Estado y la UE. La información y los cálculos necesarios para obtener estas ponderaciones se recogen en el Cuadro 7 utilizando datos de MECyD (2015b) correspondientes al año 2012.

Cuadro 7: Desglose por niveles del gasto público educativo (no financiero) en 2012

\begin{tabular}{lrr}
\hline & $\begin{array}{c}\text { Educación no } \\
\text { universitaria }\end{array}$ & $\begin{array}{c}\text { Educación } \\
\text { universitaria }\end{array}$ \\
Ministerio + CCAA & 29.472 & 8.939 \\
- ministerio neto de trasnf a ccaa & 482 & 235 \\
- Navarra & 491 & 78 \\
- País Vaco & 2.034 & 477 \\
= comunidades de régimen común y & & \\
universidades & 26.465 & 8.149 \\
- financiación específica & 264 & 9 \\
- matrículas pagadas por familias & & 1.635 \\
= total neto & 26.202 & 6.505 \\
pesos en total & $80,11 \%$ & $19,89 \%$
\end{tabular}

- Fuente: Estadística de gasto público en educación, año 2012 (MECyD, 2015b) y Anexo.

- Nota: Se excluyen los capítulos 3, 8 y 9. 
Gráfico 3: Efectos sobre las necesidades de gasto total por habitante (ngph) en 2013 de modificar el indicador educativo de la forma propuesta

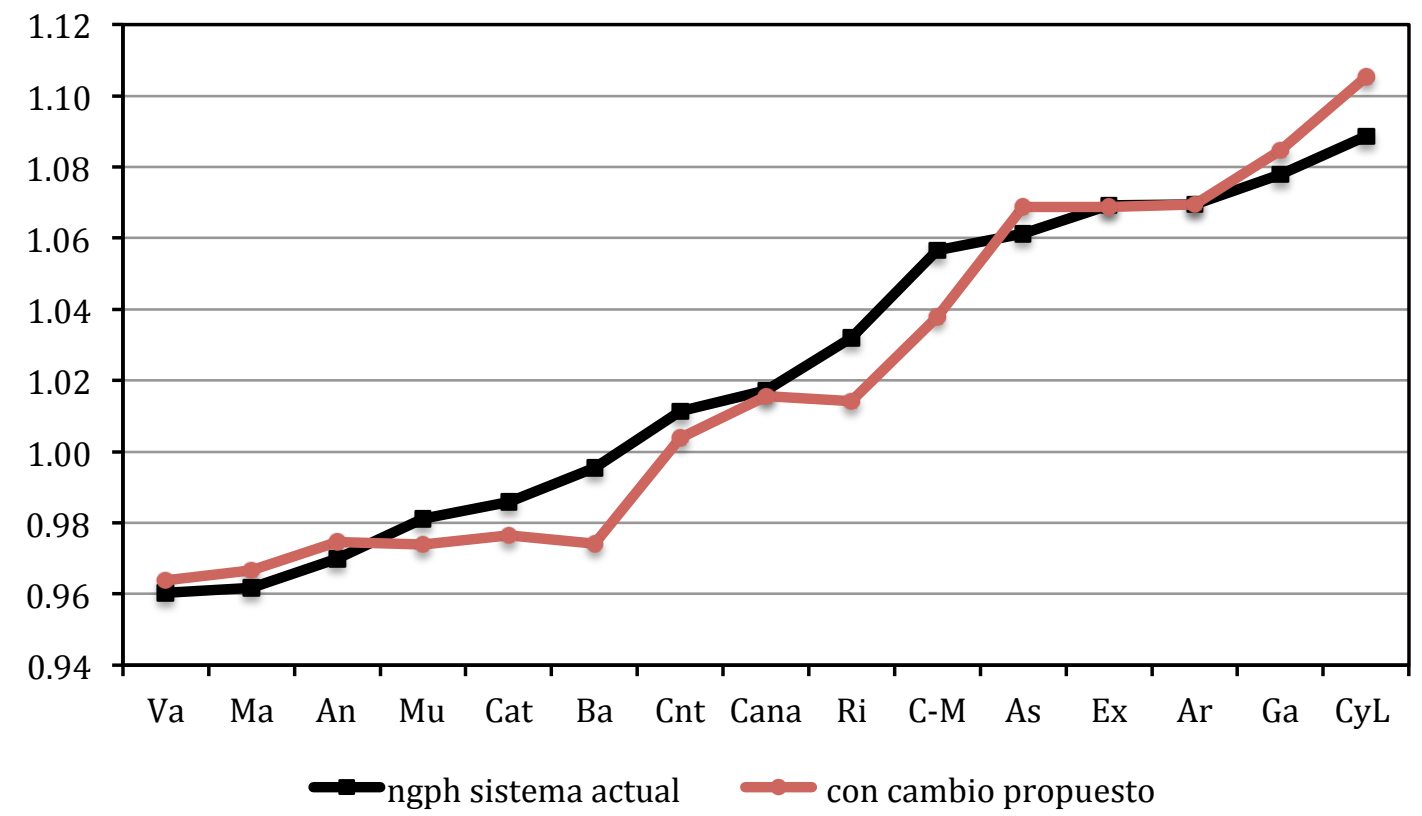

El Gráfico 3 y el Cuadro 8 muestran las implicaciones de la propuesta de modificación y desdoblamiento del indicador de necesidades de gasto educativo sobre las necesidades de gasto total por habitante de las distintas comunidades autónomas, manteniendo sin cambios el resto de la fórmula actual, incluyendo el peso total del indicador de necesidades de gasto educativo. Como cabría esperar, los cambios en las necesidades totales de gasto inducidos por la modificación propuesta son generalmente modestos, pero resultan apreciables en algunas regiones en las que existe una gran diferencia entre su participación en la población 0-16 y en el alumnado universitario del conjunto del país. Castilla y León y Baleares son los casos más extremos.

Cuadro 8: Efectos sobre las necesidades de gasto total por habitante en 2013 de modificar el indicador educativo de la forma propuesta

\begin{tabular}{lccc}
\hline & $\begin{array}{c}\text { ngph sistema } \\
\text { actual }\end{array}$ & $\begin{array}{c}\text { con cambio } \\
\text { propuesto }\end{array}$ & var $\%$ \\
Cast. y León & 1,089 & 1,105 & $1,54 \%$ \\
Asturias & 1,061 & 1,069 & $0,71 \%$ \\
Galicia & 1,078 & 1,085 & $0,65 \%$ \\
Madrid & 0,962 & 0,967 & $0,52 \%$ \\
Andalucía & 0,970 & 0,975 & $0,49 \%$ \\
Valencia & 0,960 & 0,964 & $0,36 \%$ \\
Aragón & 1,069 & 1,069 & $0,00 \%$ \\
Extremadura & 1,069 & 1,069 & $-0,05 \%$ \\
Canarias & 1,017 & 1,016 & $-0,16 \%$ \\
Murcia & 0,981 & 0,974 & $-0,72 \%$ \\
Cantabria & 1,011 & 1,004 & $-0,75 \%$ \\
Cataluña & 0,986 & 0,976 & $-0,95 \%$ \\
Rioja & 1,032 & 1,014 & $-1,75 \%$ \\
Cast. Mancha & 1,057 & 1,038 & $-1,80 \%$ \\
Baleares & 0,995 & 0,974 & $-2,16 \%$ \\
& & & \\
\hline
\end{tabular}




\subsection{Modificación del reparto de la partida de protección social}

Para aproximar las necesidades de gasto en materia de servicios sociales, en la fórmula actual se utiliza la población mayor de 64 años (65+). Éste es, efectivamente, el principal colectivo demandante de tales servicios aunque no el único, pero esto no debería suponer un problema en la práctica dado que también se incluye en la fórmula un indicador de población total que debería recoger aproximadamente la demanda de servicios sociales por otros colectivos. En principio, podría tener sentido ajustar ligeramente a la baja la ponderación de la población 65+ y al alza la de la población total en relación a las participaciones en el gasto calculadas en la sección 3, teniendo en cuenta el peso de los mayores y de otros colectivos en el gasto total en servicios sociales. En la práctica, sin embargo, es dudoso que merezca la pena intentar calcular tal ajuste dado que seguramente no resultaría fácil encontrar los datos necesarios y que la corrección sería muy menor en todo caso. Por otra parte, sí convendría investigar la posibilidad de integrar en el sistema de financiación regional la financiación estatal para el sistema de dependencia, o al menos la destinada a sus coberturas básicas, lo que aumentaría en alguna medida la ponderación total de este tramo en el cálculo de la población ajustada.

Ampliando un poco el foco, si pensamos en términos no estrictamente de servicios sociales sino de programas de protección social, incluyendo rentas mínimas de inserción y otros programas de protección de los más desfavorecidos, seguramente tendría sentido repartir una parte de esta partida de gasto social en proporción a la población en riesgo de pobreza o exclusión social, utilizando los datos de la Encuesta de Condiciones de Vida (ECV) que el INE publica anualmente (INE, 2015b).

Cuadro 9: Población en riesgo de pobreza o exclusión social, 2013

\begin{tabular}{|c|c|c|c|c|}
\hline & $\begin{array}{l}\text { población } \\
\text { padrón }\end{array}$ & $\begin{array}{c}\text { Tasa de } \\
\text { riesgo de } \\
\text { pobreza o } \\
\text { exclusión \% }\end{array}$ & $\begin{array}{l}\text { población en } \\
\text { riesgo }\end{array}$ & $\begin{array}{l}\text { peso en la } \\
\text { población en } \\
\text { riesgo }\end{array}$ \\
\hline Cataluña & 7.553 .650 & 20,1 & 1.518 .284 & $12,3 \%$ \\
\hline Galicia & 2.765 .940 & 24,3 & 672.123 & $5,5 \%$ \\
\hline Andalucía & 8.440 .300 & 38,3 & 3.232 .635 & $26,2 \%$ \\
\hline Asturias & 1.068 .165 & 21,8 & 232.860 & $1,9 \%$ \\
\hline Cantabria & 591.888 & 25,3 & 149.748 & $1,2 \%$ \\
\hline La Rioja & 322.027 & 22,2 & 71.490 & $0,6 \%$ \\
\hline Murcia & 1.472 .049 & 34,1 & 501.969 & $4,1 \%$ \\
\hline Valencia & 5.113 .815 & 31,7 & 1.621 .079 & $13,2 \%$ \\
\hline Aragón & 1.347 .150 & 19,8 & 266.736 & $2,2 \%$ \\
\hline C.-La Mancha & 2.100 .998 & 36,7 & 771.066 & $6,3 \%$ \\
\hline Canarias & 2.118 .679 & 35,5 & 752.131 & $6,1 \%$ \\
\hline Extremadura & 1.104 .004 & 36,1 & 398.545 & $3,2 \%$ \\
\hline Baleares & 1.111 .674 & 27,8 & 309.045 & $2,5 \%$ \\
\hline Madrid & 6.495 .551 & 20,1 & 1.305 .606 & $10,6 \%$ \\
\hline Cast. y León & 2.519 .875 & 20,8 & 524.134 & $4,3 \%$ \\
\hline total & 44.125 .765 & & 12.327 .451 & $100,0 \%$ \\
\hline
\end{tabular}

- Fuente: INE (2015b) 
Gráfico 4: Efectos sobre las necesidades de gasto total por habitante (ngph) en 2013 de incorporar la población en riesgo de pobreza y exclusión social con un peso de 1/3 de la ponderación total de la partida de servicios sociales

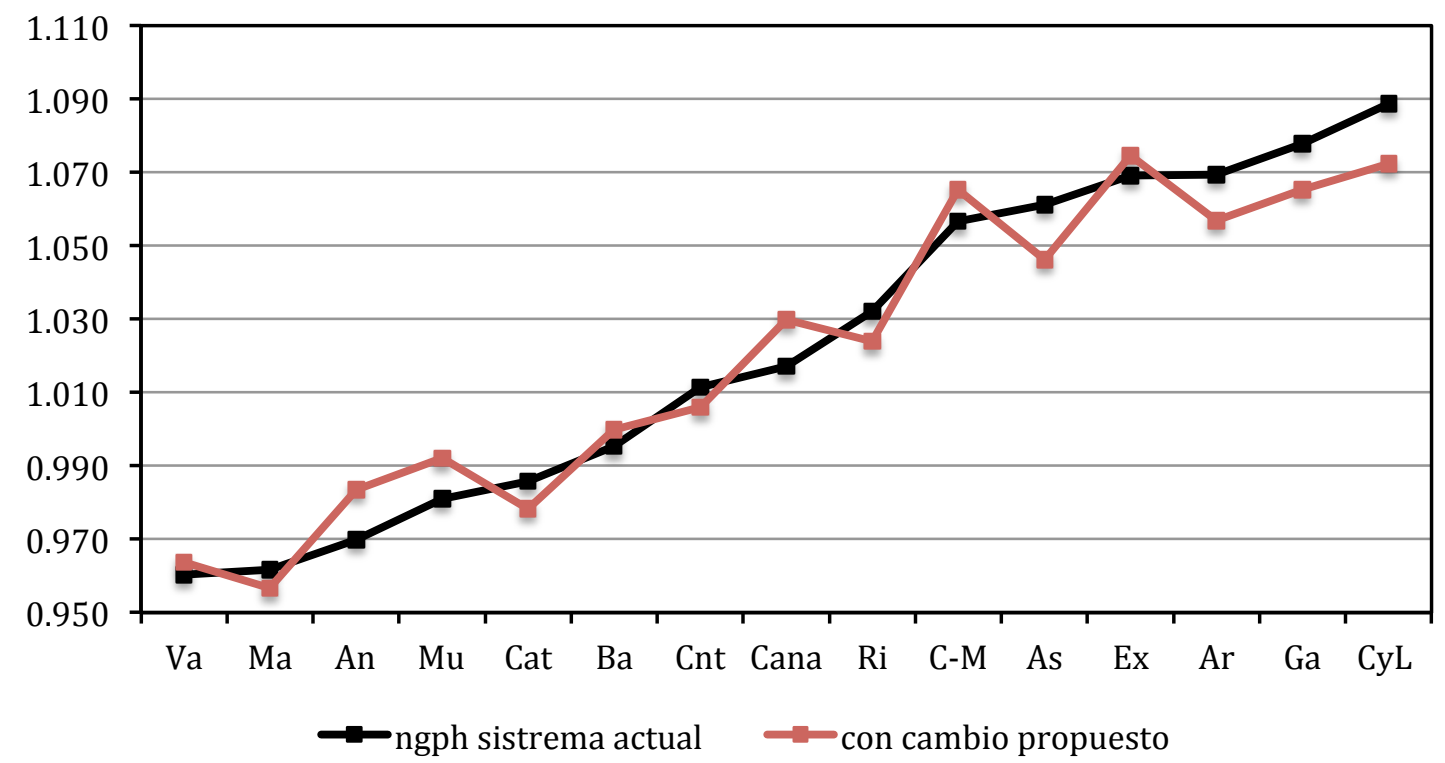

Cuadro 10: Efectos sobre las necesidades de gasto por habitante en 2013 de incorporar la población en riesgo de pobreza y exclusión social con un peso de 1/3 de la ponderación total de la partida de protección social

\begin{tabular}{lccc}
\hline & $\begin{array}{c}\text { ngph sistema } \\
\text { actual }\end{array}$ & $\begin{array}{c}\text { con 17cambio } \\
\text { propuesto }\end{array}$ & var \% \\
Andalucía & 0,970 & 0,983 & $+1,41 \%$ \\
Canarias & 1,017 & 1,030 & $+1,25 \%$ \\
Murcia & 0,981 & 0,992 & $+1,14 \%$ \\
C. la Mancha & 1,057 & 1,065 & $+0,82 \%$ \\
Extremadura & 1,069 & 1,075 & $+0,51 \%$ \\
Baleares & 0,995 & 1,000 & $+0,46 \%$ \\
Valencia & 0,960 & 0,964 & $+0,34 \%$ \\
Madrid & 0,962 & 0,957 & $-0,52 \%$ \\
Cantabria & 1,011 & 1,006 & $-0,54 \%$ \\
Cataluña & 0,986 & 0,978 & $-0,76 \%$ \\
Rioja & 1,032 & 1,024 & $-0,78 \%$ \\
Aragón & 1,069 & 1,057 & $-1,17 \%$ \\
Galicia & 1,078 & 1,065 & $-1,17 \%$ \\
Asturias & 1,061 & 1,046 & $-1,42 \%$ \\
Cast y León & 1,089 & 1,072 & $-1,51 \%$ \\
\hline
\end{tabular}

A falta de datos sobre el peso presupuestario de los distintos programas relevantes, en lo que sigue exploraré las implicaciones de repartir un tercio de la partida de protección social en proporción a este indicador, reduciendo de forma correspondiente el peso de la población 65+. El Cuadro 9 muestra el desglose por regiones de la población en riesgo de pobreza o exclusión en 2013, calculado aplicando las correspondientes tasas de riesgo de la ECV a la población empadronada y el Gráfico 4 y el Cuadro 10 resumen los efectos sobre las necesidades de gasto regionales del cambio propuesto en la fórmula de reparto. En general, los efectos son modestos 
(de no más de un 1,5\% al alza o a la baja) y favorecen a las regiones de menor renta a expensas de las más ricas y las más envejecidas.

\section{4. ¿Otras modificaciones de los indicadores de necesidades de gasto?}

En este apartado se pasa revista al resto de variables de reparto incluidas en la fórmula actual. En términos generales, no parece haber razones claras para modificar sus definiciones o para alterar sus pesos.

\section{Sanidad}

$\mathrm{El}$ indicador de necesidades de gasto sanitario que se utiliza en el modelo actual es una variable de población protegida por el SNS ponderada por el nivel relativo de gasto sanitario que se observa en cada tramo de edad. El indicador resulta atractivo en términos intuitivos y existe además cierta evidencia empírica de que recoge adecuadamente las necesidades relativas de gasto sanitario (véase de la Fuente y Gundín, 2009). En principio, por tanto, no parece haber razones para revisar este indicador.

Por otra parte, la reciente revisión del procedimiento de cálculo de la población protegida equivalente (véase de la Fuente, 2015, pp. 11-12) plantea algunas dudas. En coherencia con el cambio en la normativa relevante, en la liquidación de 2013 se han excluido de la población protegida a algunos grupos de población, entre los que destacan los extranjeros que pese a estar ilegalmente en el país están empadronados en España, que han perdido en parte su derecho a la asistencia sanitaria pública. Puesto que la exclusión de la sanidad pública no es total (pues se mantiene el acceso para los niños y las embarazadas y en casos de emergencia) y además ha sido cuestionada por numerosas comunidades autónomas, en función de lo que finalmente se decida sobre el nivel de protección de este colectivo, convendría seguramente asignarle una ponderación distinta de cero a efectos del cálculo de la población protegida equivalente.

\section{Correcciones por variables geográficas}

La literatura existente no resulta de demasiada ayuda a la hora de fijar los pesos de los factores geográficos en la fórmula de necesidades de gasto. Los resultados de la Fuente y Gundín (2009) para el caso de la sanidad son poco concluyentes. Este estudio sugiere que la superficie y la insularidad, pero no la dispersión de la población, podrían tener un efecto modesto sobre al menos algunas partidas de costes sanitarios, pero no ofrece ninguna indicación de que los pesos de estos factores estén subestimados en la fórmula actual.

Para otros servicios autonómicos, no he conseguido encontrar prácticamente ninguna evidencia relevante. En relación con la insularidad, tanto el Gobierno canario como el de las Islas Baleares han patrocinado estudios que pretenden cuantificar sus costes (Murillo et al, 1992 y UIB, 2014). Ambos trabajos, sin embargo, se centran en la cuantificación del impacto de este factor sobre el desarrollo regional, más que sobre los sobrecostes en materia de servicios públicos que es lo que aquí nos interesa. 
Cuadro 11: Peso del gasto en bienes y servicios dentro del gasto no financiero total

\begin{tabular}{lrrr}
\hline & total CCAA & Canarias & \multicolumn{1}{c}{ Baleares } \\
Gasto corriente en bienes y servicios & 28.693 .900 & 1.036 .585 & 449.842 \\
gasto total no financiero & 138.717 .560 & 6.455 .973 & 3.106 .932 \\
peso de bienes y servicios en el gasto total & $20,7 \%$ & $16,1 \%$ & $14,5 \%$ \\
\hline
\end{tabular}

- Fuente: MHAP (2015a)

Algunos cálculos muy preliminares sugieren que es poco probable que la actual fórmula de necesidades de gasto subestime los costes de la insularidad para el sector público autonómico. Como los dos estudios citados destacan, las necesidades de transporte seguramente tienen un peso importante dentro de los costes de la insularidad. Desafortunadamente, puesto que no tenemos datos homogéneos de gasto autonómico en transportes, sólo podemos trabajar con datos agregados de capítulo 2, donde se recoge el gasto corriente en la compra de bienes y servicios. El Cuadro 11 muestra que el peso de esta partida en el gasto total no financiero de las comunidades insulares es inferior al promedio nacional, que está en torno al $20 \%$ del gasto total. Aunque ciertamente puede haber otros factores que compensen un elevado gasto insular en transportes, los datos no sugieren que las administraciones regionales de Baleares y Canarias tengan costes de funcionamiento muy superiores a los de las demás comunidades autónomas. Dado el reducido peso del gasto en transportes en el total, además, las primas de necesidades de gasto ligadas a la insularidad que se les reconocen a las dos comunidades insulares (véase el Cuadro 2) parecen en principio más que adecuadas, al menos a falta de evidencia directa en otro sentido.

\section{4. ¿Nuevos indicadores de necesidades de gasto?}

¿Deberíamos incluir variables adicionales en la fórmula de necesidades de gasto? Dos posibilidades que han sido sugeridas son la población flotante o turística y la población inmigrante. En esta sección se exploran ambas posibilidades.

\section{Población flotante}

En algunas regiones tiene un peso importante la población flotante, compuesta por turistas españoles y extranjeros y por personas desplazadas temporalmente por trabajo u otros motivos. El tamaño de este colectivo puede aproximarse utilizando la información que proporcionan las encuestas turísticas EGATUR (Encuesta de Gasto Turístico) y FAMILITUR (Movimientos Turísticos de los Españoles) del Instituto de Estudios Turísticos (IET, 2013 a y b). Como se observa en el Cuadro 10, el peso medio de este componente de la población es un apreciable $5 \%$, que llega al 25\% en el caso de Baleares.

¿Qué efecto tiene la población flotante sobre las necesidades de gasto de las comunidades autónomas? Ciertamente, su impacto es mucho menor que el de la población residente pues los visitantes temporales no consumen servicios educativos o sociales ni reciben ayudas a la vivienda entre otras muchas cosas. Sí que demandan esporádicamente atención sanitaria, 


\begin{tabular}{lrrrrr}
\hline \multicolumn{7}{c}{$\begin{array}{c}\text { Población } \\
\text { residente }\end{array}$} & $\begin{array}{c}\text { visitantes } \\
\text { extranjeros }\end{array}$ & $\begin{array}{r}\text { visitantes del } \\
\text { resto de España }\end{array}$ & $\begin{array}{r}\text { total población } \\
\text { flotante media }\end{array}$ & $\begin{array}{c}\text { como\% de la } \\
\text { pobl. residente }\end{array}$ \\
Cataluña & 7.562 .279 & 283.843 & 64.699 & 348.542 & $4,61 \%$ \\
Galicia & 2.773 .719 & 19.827 & 56.129 & 75.956 & $2,74 \%$ \\
Andalucía & 8.445 .143 & 230.003 & 143.726 & 373.729 & $4,43 \%$ \\
Asturias & 1.072 .763 & 8.335 & 28.071 & 36.406 & $3,39 \%$ \\
Cantabria & 592.875 & 73 & 38.631 & 38.704 & $6,53 \%$ \\
La Rioja & 322.818 & 953 & 15.869 & 16.822 & $5,21 \%$ \\
Murcia & 1.473 .249 & 2.084 & 3.638 & 5.722 & $0,39 \%$ \\
Valencia & 5.121 .541 & 173.739 & 153.261 & 327.000 & $6,38 \%$ \\
Aragón & 1.348 .309 & 7.201 & 37.125 & 44.326 & $3,29 \%$ \\
Cast.-La Mancha & 2.111 .443 & 5.242 & 79.839 & 85.081 & $4,03 \%$ \\
Canarias & 2.118 .512 & 264.625 & 27.778 & 292.403 & $13,80 \%$ \\
Extremadura & 1.106 .067 & 4.232 & 39.047 & 43.279 & $3,91 \%$ \\
Baleares & 1.115 .557 & 248.345 & 31.901 & 280.246 & $25,12 \%$ \\
Madrid & 6.497 .056 & 88.824 & 69.093 & 157.917 & $2,43 \%$ \\
Castilla y León & 2.532 .977 & 19.991 & 124.807 & 144.798 & $5,72 \%$ \\
total & 44.194 .308 & 1.357 .317 & 913.614 & 2.270 .931 & $5,14 \%$ \\
& & & & &
\end{tabular}

- Nota: población residente es población media de acuerdo con el padrón, calculada como el promedio de las correspondientes a 1 de enero de 2012 y a 1 de enero de 2013.

- Fuente: MHAP (2015b). Anexo 5, Cuadros A5.10 y A5.24

generalmente atención primaria o de urgencias, lo que puede suponer un coste apreciable en las regiones más turísticas. Sin embargo, la forma más razonable de sufragar el coste de esa atención es mediante su facturación al territorio de residencia de los atendidos. Si los acuerdos y sistemas necesarios a estos efectos no están plenamente desarrollados en la actualidad, su finalización debería ser un objetivo prioritario y podría requerir una actuación estatal y quizás una financiación especial de carácter transitorio, pero no una financiación permanente a través del sistema de financiación que podría además reducir los incentivos para resolver este problema de la forma más adecuada. En cualquier caso, antes de descartar la posibilidad de incorporar la población flotante a la fórmula de necesidades de gasto, aunque fuera de forma transitoria, sería conveniente recabar información de las administraciones implicadas sobre si los mecanismos de facturación de los costes originados por los desplazados que provienen de otras comunidades o de países extranjeros funcionan o no razonablemente bien en la práctica.

Por otra parte, la población flotante sí puede generar una fuerte presión sobre los servicios de los municipios turísticos en áreas como la limpieza, la recogida de basuras y la policía. Una vez más, sin embargo, la forma más razonable de financiar los costes generados por los transeúntes es probablemente a través de una tasa local, posiblemente sobre pernoctaciones en hoteles y otros establecimientos turísticos, y no a través del sistema general de financiación (local en este caso).

Por lo tanto, en principio no parece aconsejable añadir la población flotante a las variables de reparto del sistema de financiación regional. A efectos meramente ilustrativos, he calculado las implicaciones que tendría la incorporación de esta variable a la fórmula de reparto con un peso del 1\%, acompañada de una reducción de la misma cuantía en el peso de la población total. Los 
resultados se resumen en el Cuadro 13 y el Gráfico 5. Como resulta obvio a la luz del Cuadro 12, la incorporación de la población flotante beneficiaría muy especialmente a las dos comunidades insulares.

Gráfico 5: Efectos sobre las necesidades de gasto total por habitante (ngph) en 2013 de incorporar la población flotante con un peso del $1 \%$

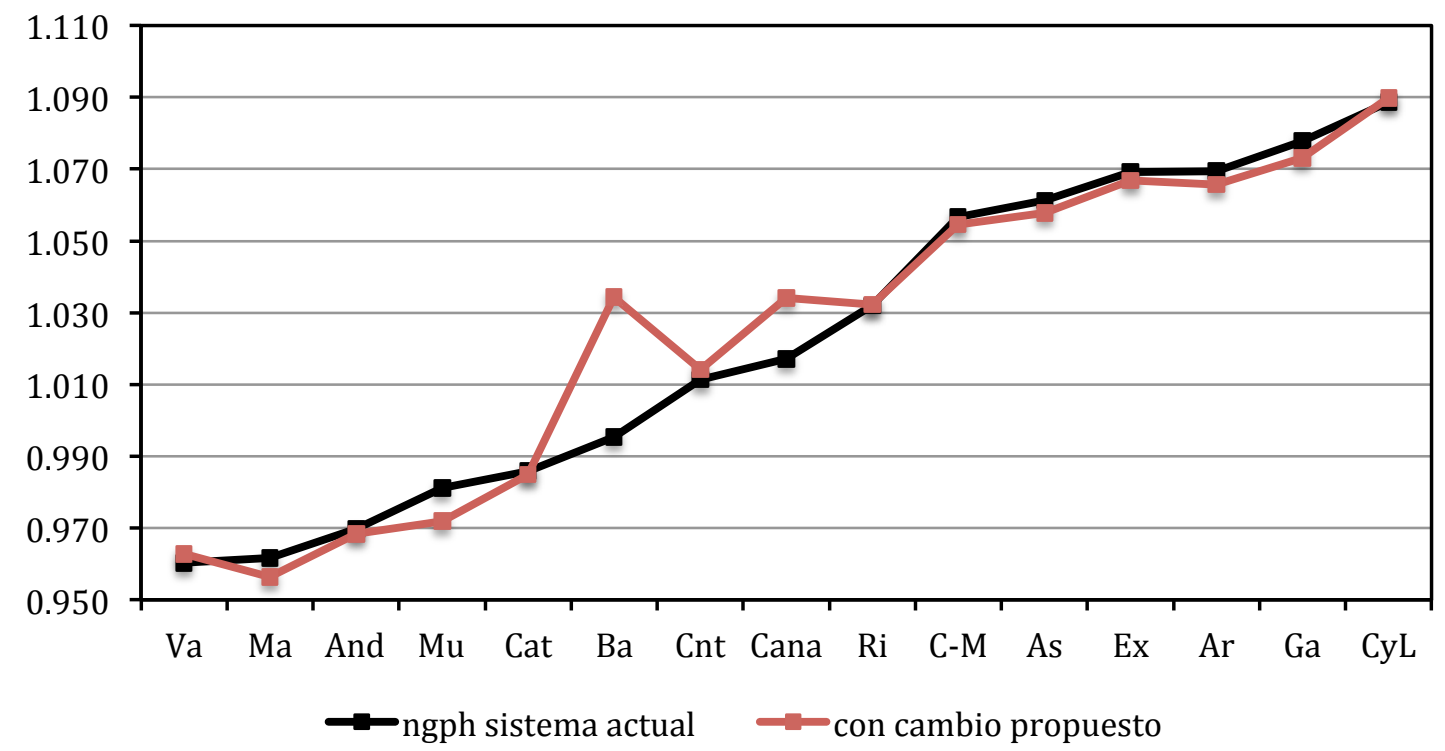

Cuadro 13: Efectos sobre las necesidades de gasto por habitante en 2013 de introducir la población flotante con una ponderación del $1 \%$

\begin{tabular}{lccc}
\hline & ngph sistema & con 21 osts & \\
actual & fijos & var $\%$ \\
Baleares & 0,995 & 1,034 & $+3,92 \%$ \\
Canarias & 1,017 & 1,034 & $+1,65 \%$ \\
Cantabria & 1,011 & 1,014 & $+0,27 \%$ \\
Valencia & 0,960 & 0,963 & $+0,25 \%$ \\
Cast. Y León & 1,089 & 1,090 & $+0,11 \%$ \\
La Rioja & 1,032 & 1,032 & $+0,01 \%$ \\
Cataluña & 0,986 & 0,985 & $-0,10 \%$ \\
Andalucia & 0,970 & 0,968 & $-0,14 \%$ \\
C.- La Mancha & 1,057 & 1,055 & $-0,20 \%$ \\
Extremadura & 1,069 & 1,067 & $-0,22 \%$ \\
Asturias & 1,061 & 1,058 & $-0,32 \%$ \\
Aragón & 1,069 & 1,066 & $-0,34 \%$ \\
Galicia & 1,078 & 1,073 & $-0,43 \%$ \\
Madrid & 0,962 & 0,956 & $-0,55 \%$ \\
Murcia & 0,981 & 0,972 & $-0,94 \%$ \\
total & 1,000 & 1,000 & $0,00 \%$ \\
& & & \\
\hline
\end{tabular}

\section{Población inmigrante}

España experimentó en la pasada década un fuerte influjo migratorio. En la actualidad hay más de cinco millones de extranjeros residiendo en nuestro país. Algo menos de la mitad provienen de otros países miembros de la Unión Europea. En la otra mitad dominan, con pesos aproximadamente iguales, los latinoamericanos y los inmigrantes procedentes de África y Asia. 
El Cuadro 14 muestra el desglose por comunidades autónomas y por principales regiones de origen de la población extranjera con datos del padrón de 2013.

Cuadro 14: Población extranjera y total empadronada a 1 de enero de 2013

\begin{tabular}{|c|c|c|c|c|c|c|c|c|}
\hline & $\begin{array}{c}\text { población } \\
\text { extranjera } \\
\text { empadro- } \\
\text { nada }\end{array}$ & $\begin{array}{c}\text { como \% } \\
\text { de la pob } \\
\text { total }\end{array}$ & $\begin{array}{l}\text { Unión } \\
\text { Europea }\end{array}$ & $\begin{array}{l}\text { \% de la } \\
\text { pob total }\end{array}$ & $\begin{array}{l}\text { America } \\
\text { del Sury } \\
\text { Central }\end{array}$ & $\begin{array}{l}\% \text { de la } \\
\text { pob total }\end{array}$ & $\begin{array}{l}\text { Asia y } \\
\text { Africa }\end{array}$ & $\begin{array}{l}\% \text { de la } \\
\text { pob total }\end{array}$ \\
\hline Baleares & 224.406 & $25,29 \%$ & 118.766 & $10,68 \%$ & 50.507 & $4,54 \%$ & 47.066 & $4,23 \%$ \\
\hline Valencia & 863.891 & $20,33 \%$ & 495.473 & $9,69 \%$ & 140.622 & $2,75 \%$ & 163.501 & $3,20 \%$ \\
\hline Murcia & 231.022 & $18,62 \%$ & 62.041 & $4,21 \%$ & 67.078 & $4,56 \%$ & 90.966 & $6,18 \%$ \\
\hline Cataluña & 1.158 .472 & $18,11 \%$ & 306.466 & $4,06 \%$ & 315.716 & $4,18 \%$ & 460.674 & $6,10 \%$ \\
\hline Madrid & 960.121 & $17,35 \%$ & 362.370 & $5,58 \%$ & 349.014 & $5,37 \%$ & 197.115 & $3,03 \%$ \\
\hline Canarias & 301.234 & $16,57 \%$ & 175.228 & $8,27 \%$ & 65.832 & $3,11 \%$ & 47.853 & $2,26 \%$ \\
\hline la Rioja & 44.404 & $15,99 \%$ & 18.111 & $5,62 \%$ & 8.872 & $2,76 \%$ & 15.229 & $4,73 \%$ \\
\hline Aragón & 173.653 & $14,80 \%$ & 89.425 & $6,64 \%$ & 31.961 & $2,37 \%$ & 47.214 & $3,50 \%$ \\
\hline Cast la Mancha & 220.919 & $11,75 \%$ & 115.256 & $5,49 \%$ & 45.671 & $2,17 \%$ & 52.673 & $2,51 \%$ \\
\hline Andalucía & 729.725 & $9,46 \%$ & 372.183 & $4,41 \%$ & 116.293 & $1,38 \%$ & 197.469 & $2,34 \%$ \\
\hline Cast y León & 164.780 & $7,00 \%$ & 83.474 & $3,31 \%$ & 42.193 & $1,67 \%$ & 34.089 & $1,35 \%$ \\
\hline Cantabria & 38.530 & $6,96 \%$ & 13.487 & $2,28 \%$ & 14.443 & $2,44 \%$ & 5.756 & $0,97 \%$ \\
\hline Asturias & 48.394 & $4,75 \%$ & 19.389 & $1,82 \%$ & 18.214 & $1,71 \%$ & 8.249 & $0,77 \%$ \\
\hline Extremadura & 41.677 & $3,92 \%$ & 20.380 & $1,85 \%$ & 8.665 & $0,78 \%$ & 11.575 & $1,05 \%$ \\
\hline total & 5.201 .228 & $14,38 \%$ & 2.252 .049 & $5,45 \%$ & 1.275 .081 & $3,08 \%$ & 1.379 .429 & $3,34 \%$ \\
\hline
\end{tabular}

Resulta indudable que la acogida e integración de grandes cantidades de población extranjera comporta unos costes que pueden ser significativos, especialmente en los primeros años tras su llegada. Con el fin de identificar la mejor forma de financiarlos, convendría realizar un análisis sistemático de la magnitud de estos costes, de los colectivos específicos que los generan y de por qué vías lo hacen y de las administraciones que los soportan. Es muy posible que este ejercicio pueda aconsejar la inclusión de algún indicador del stock o del flujo reciente de determinados grupos de inmigrantes entre las variables de reparto del sistema de financiación regional, pero no es posible definir este indicador o fijar su ponderación de una forma razonable sin un estudio previo cuidadoso de la cuestión.

\section{5. ¿Correcciones por precios y por renta relativa?}

Dos factores importantes de costes diferenciales que la formula actual de necesidades de gasto no recoge son los ligados a las diferencias en niveles de precios y de renta per cápita que existen entre regiones.

Aunque la introducción de una corrección regional por niveles de precios es seguramente una buena idea, su diseño puede resultar algo más complicada de lo que podría parecer a primera vista. En particular, no sería correcto ajustar la financiación total de cada región al alza o a la baja en proporción a su nivel relativo de precios al consumo porque las administraciones regionales no consumen las mismas cosas que los hogares y porque muchas de las cosas que consumen (como medicinas, equipos médicos, servicios de consultoría o material de oficina) se compran en mercados nacionales o internacionales, en condiciones en principio similares para 
todas las autonomías. Idealmente, por tanto, habría que pensar en la elaboración de un índice de precios específico para el gasto público autonómico que mostraría seguramente una menor dispersión regional que el IPC. En su ausencia, y dado que la partida de personal tiene un peso muy elevado en el gasto autonómico, se podría trabajar con el componente salarial de este índice, que resulta sencillo de elaborar y seguramente tendría un peso muy elevado en el indicador ideal. Así pues, un criterio razonable para realizar una corrección aproximada por precios podría ser el de dotar a las comunidades autónomas de los recursos necesarios para que todas ellas puedan, si así lo deciden, pagar salarios medios con el mismo poder adquisitivo, de forma que puedan atraer personal con niveles similares de cualificación.

En cuanto al segundo factor, el nivel de renta per cápita puede tener un efecto muy apreciable sobre el gasto autonómico a través de la demanda de servicios sociales y del grado de utilización de la sanidad y de la educación públicas, que tienden a ser sustituidas de forma creciente por seguros sanitarios y colegios privados según aumenta el nivel de renta.

Puesto que el diseño de ambas correcciones plantea problemas técnicos y conceptuales, mi propuesta en este punto no sería la de introducirlas inmediatamente en la fórmula de reparto del sistema sino la de analizar en detalle esta posibilidad para ir desarrollando las herramientas necesarias de cara a su implementación a medio plazo. Puesto que las dos correcciones tendrían efectos contrapuestos en función del nivel de renta regional, su implementación debería realizarse, en su caso, de forma simultánea para evitar penalizar indebidamente a algún grupo de regiones. A título ilustrativo, en el resto de esta sección se presentan algunos cálculos muy preliminares sobre las implicaciones de cada una de estas correcciones.

\section{1. ¿Una corrección por niveles de precios?}

Como se ha visto más arriba, un índice regional de precios relativos al consumo no sería directamente utilizable para neutralizar los efectos de precios sobre la financiación de las comunidades autónomas, pero sí sería un ingrediente crucial para calcular la corrección necesaria, al menos en lo que respecta a su componente de personal. Desafortunadamente, sin embargo, en España no contamos con un índice de estas características. Aunque el INE recoge regularmente la información necesaria para construirlo, sin embargo no lo elabora o al menos no lo publica. ${ }^{6}$ La única excepción corresponde al año 1989 cuando, por encargo de Eurostat, el INE elaboró un índice de precios relativos al consumo por regiones que eventualmente se publicó en Lorente (1992).

Actualizando este indicador con la variación observada de los IPCs regionales, es posible construir un índice aproximado de precios relativos en la actualidad. Este es el enfoque que se utiliza en de la Fuente y Gundín (2008b) para ofrecer una primera estimación de las implicaciones de introducir una corrección por precios en la fórmula de necesidades de gasto del sistema de financiación regional. Esta es también una de las vías utilizadas en un trabajo

\footnotetext{
${ }^{6}$ Los IPCs regionales no reflejan las diferencias existentes entre regiones en niveles de precios. Esto es, en el año que se toma como base para la elaboración de este indicador, el valor del mismo se iguala a 100 en todas las regiones a pesar de que los niveles de precios no son iguales en todas ellas.
} 
reciente de Costa et al (2015) para construir un índice de precios relativos regionales. ${ }^{7}$ Estos autores, sin embargo, utilizan también otros dos métodos para construir estimaciones alternativas de este índice. El primero consiste en estimar una relación entre nivel de precios y PIB per cápita con datos de países de la OCDE, que luego se aplica a las regiones españolas para estimar el índice deseado. El segundo se basa en la estimación de una ecuación de gasto total con microdatos de hogares en la que se introducen variables ficticias regionales y por categorías de productos para recoger efectos de precios. Tras estimar las distintas especificaciones, los autores avanzan una "propuesta de síntesis" para estimar el deseado índice de precios relativos como una media ponderada de los obtenidos por los dos últimos procedimientos indicados.

\section{Gráfico 6: Estimaciones alternativas del índice de precios relativos regionales Costa et al (2015)}

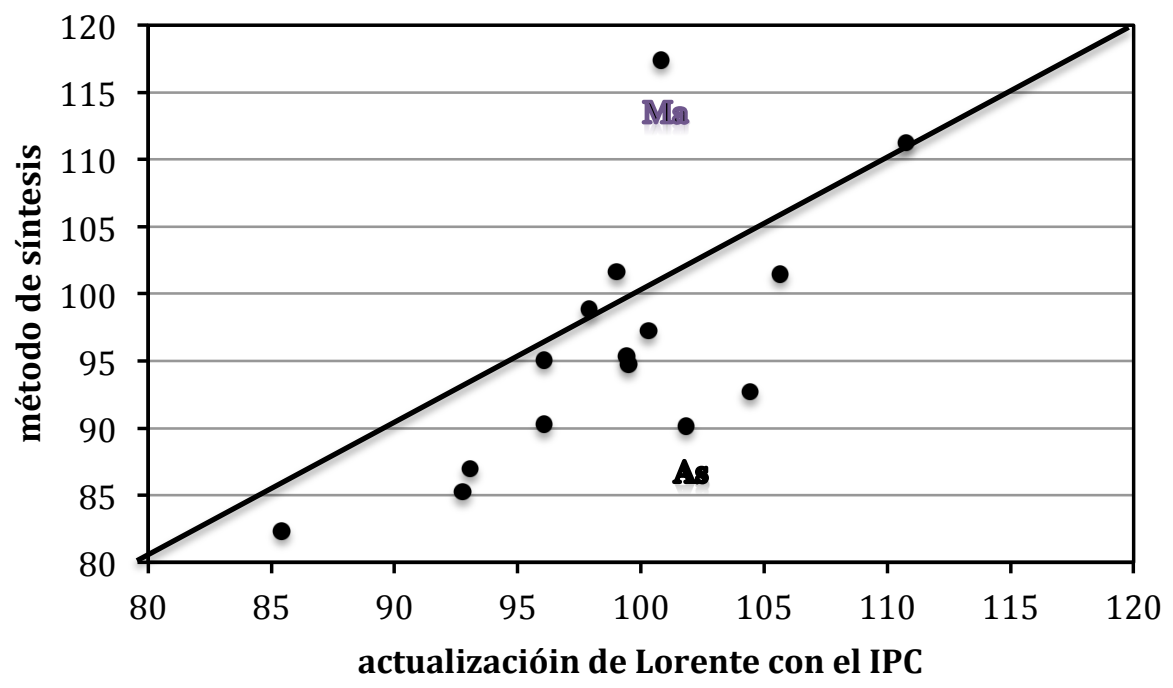

El Gráfico 6 muestra la relación existente entre dos de los índices de precios estimados por Costa et al tras renormalizarlos por el valor correspondiente al promedio del territorio de régimen común. Este promedio se calcula ponderando los índices regionales por el peso de cada región en la población total del territorio de referencia y no por su peso en el PIB. Como referencia, el gráfico muestra la diagonal sobre la que se concentrarían todas las regiones si ambas alternativas generasen el mismo resultado. Como se observa en el gráfico, esto no suele ser así, destacando los casos de Madrid y Asturias, donde las dos metodologías producen resultados muy distintos. En esta situación, sería muy arriesgado utilizar cualquiera de los dos índices para introducir ajustes a la financiación regional que podrían ascender a varios cientos de millones de euros. Antes de proceder a calcular tales correcciones, resultaría imprescindible contar con un índice fiable de precios relativos que debería ser elaborado anualmente por el INE a partir de datos directos y detallados de precios por regiones.

\footnotetext{
${ }^{7}$ Costa et al introducen una importante corrección adicional. Los autores observan que el índice de precios relativos que recoge Lorente (1992) se refiere realmente a los precios de 17 ciudades que en la mayor parte de los casos son las capitales de las correspondientes comunidades autónomas. Para obtener un indicador válido para el conjunto de cada territorio hay que multiplicar la variable original por un factor de corrección que se construye con información publicada por el INE en 1983 sobre los niveles de precios de las ciudades relevantes en relación con el promedio de su comunidad autónoma (p. 28 en Costa et al).
} 
Cuadro 15: Cálculo de la corrección parcial a las necesidades de gasto regionales por diferencias en el nivel de precios, 2013

a. actualización de Lorente

\begin{tabular}{lrrrrrr}
\hline & $\begin{array}{c}\text { diferencial } \\
\text { de precios }\end{array}$ & $\begin{array}{c}\text { parte a } \\
\text { compensar }\end{array}$ & $\begin{array}{c}\text { pob } \\
\text { ajustada } \\
\text { original }\end{array}$ & $\begin{array}{c}\text { pob ajustada } \\
\text { revisada } \\
\text { provisional }\end{array}$ & $\begin{array}{c}\text { pob ajustada } \\
\text { revisada final }\end{array}$ & variacion \% \\
Cataluña & & & & & & \\
Galicia & $10,76 \%$ & $4,23 \%$ & 7.446 .814 & 7.762 .085 & 7.764 .501 & $+4,27 \%$ \\
Andalucia & $-0,49 \%$ & $-0,19 \%$ & 2.981 .328 & 2.975 .527 & 2.976 .454 & $-0,16 \%$ \\
Asturias & $-3,91 \%$ & $-1,54 \%$ & 8.185 .501 & 8.059 .540 & 8.062 .049 & $-1,51 \%$ \\
Cantabria & $1,82 \%$ & $0,71 \%$ & 1.133 .620 & 1.141 .723 & 1.142 .078 & $+0,75 \%$ \\
La Rioja & $-1,00 \%$ & $-0,39 \%$ & 598.634 & 596.286 & 596.472 & $-0,36 \%$ \\
Murcia & $4,43 \%$ & $1,74 \%$ & 332.334 & 338.126 & 338.231 & $+1,77 \%$ \\
Valencia & $0,31 \%$ & $0,12 \%$ & 1.444 .162 & 1.445 .921 & 1.446 .371 & $+0,15 \%$ \\
Aragón & $-0,60 \%$ & $-0,23 \%$ & 4.910 .946 & 4.899 .449 & 4.900 .975 & $-0,20 \%$ \\
C.-La Mancha & $-2,10 \%$ & $-0,83 \%$ & 1.440 .627 & 1.428 .711 & 1.429 .156 & $-0,80 \%$ \\
Canarias & $-6,93 \%$ & $-2,72 \%$ & 2.220 .075 & 2.159 .579 & 2.160 .251 & $-2,69 \%$ \\
Extremadura & $-7,23 \%$ & $-2,84 \%$ & 2.155 .082 & 2.093 .801 & 2.094 .453 & $-2,81 \%$ \\
Baleares & $-14,57 \%$ & $-5,73 \%$ & 1.180 .337 & 1.112 .707 & 1.113 .053 & $-5,70 \%$ \\
Madrid & $5,64 \%$ & $2,22 \%$ & 1.106 .547 & 1.131 .081 & 1.131 .434 & $+2,25 \%$ \\
Cast. Y León & $0,81 \%$ & $0,32 \%$ & 6.246 .404 & 6.266 .357 & 6.268 .308 & $+0,35 \%$ \\
total & $-3,91 \%$ & $-1,54 \%$ & 2.743 .355 & 2.701 .139 & 2.701 .980 & $-1,51 \%$ \\
& & & 44.125 .765 & 44.112 .030 & 44.125 .765 & $0,00 \%$ \\
& & & & & & \\
\hline
\end{tabular}

b. propuesta de síntesis de los autores

\begin{tabular}{lrrrrrr}
\hline & $\begin{array}{c}\text { diferencial } \\
\text { de precios }\end{array}$ & $\begin{array}{c}\text { parte a } \\
\text { compensar }\end{array}$ & $\begin{array}{c}\text { pob } \\
\text { ajustada } \\
\text { original }\end{array}$ & $\begin{array}{c}\text { pob ajustada } \\
\text { revisada } \\
\text { provisional }\end{array}$ & $\begin{array}{c}\text { pob ajustada } \\
\text { revisada final }\end{array}$ & variacion \% \\
Cataluñ & $11,28 \%$ & $4,44 \%$ & 7.446 .814 & 7.777 .097 & 7.784 .621 & $+4,54 \%$ \\
Galicia & $-5,24 \%$ & $-2,06 \%$ & 2.981 .328 & 2.919 .914 & 2.922 .739 & $-1,97 \%$ \\
Andalucía & $-4,93 \%$ & $-1,94 \%$ & 8.185 .501 & 8.026 .791 & 8.034 .556 & $-1,84 \%$ \\
Asturias & $-9,85 \%$ & $-3,88 \%$ & 1.133 .620 & 1.089 .688 & 1.090 .742 & $-3,78 \%$ \\
Cantabria & $1,63 \%$ & $0,64 \%$ & 598.634 & 602.484 & 603.067 & $+0,74 \%$ \\
La Rioja & $-7,29 \%$ & $-2,87 \%$ & 332.334 & 322.807 & 323.119 & $-2,77 \%$ \\
Murcia & $-2,78 \%$ & $-1,09 \%$ & 1.444 .162 & 1.428 .396 & 1.429 .778 & $-1,00 \%$ \\
Valencia & $-4,62 \%$ & $-1,82 \%$ & 4.910 .946 & 4.821 .670 & 4.826 .335 & $-1,72 \%$ \\
Aragón & $-1,13 \%$ & $-0,45 \%$ & 1.440 .627 & 1.434 .199 & 1.435 .586 & $-0,35 \%$ \\
C.-La Mancha & $-13,03 \%$ & $-5,13 \%$ & 2.220 .075 & 2.106 .274 & 2.108 .312 & $-5,03 \%$ \\
Canarias & $-14,77 \%$ & $-5,81 \%$ & 2.155 .082 & 2.029 .832 & 2.031 .796 & $-5,72 \%$ \\
Extremadura & $-17,65 \%$ & $-6,94 \%$ & 1.180 .337 & 1.098 .405 & 1.099 .468 & $-6,85 \%$ \\
Baleares & $1,43 \%$ & $0,56 \%$ & 1.106 .547 & 1.112 .769 & 1.113 .846 & $+0,66 \%$ \\
Madrid & $17,43 \%$ & $6,86 \%$ & 6.246 .404 & 6.674 .644 & 6.681 .101 & $+6,96 \%$ \\
Cast. y León & $-9,75 \%$ & $-3,84 \%$ & 2.743 .355 & 2.638 .146 & 2.640 .699 & $-3,74 \%$ \\
total & & & 44.125 .765 & 44.083 .118 & 44.125 .765 & $0,00 \%$ \\
& & & & & & \\
\hline
\end{tabular}

A título ilustrativo, en los dos paneles del Cuadro 15 se calculan las correcciones a las necesidades de gasto regionales generadas por ambos índices de precios siguiendo el procedimiento indicado más arriba, esto es, corrigiendo únicamente las diferencias ligadas a los costes de personal. En primer lugar, el diferencial de precios con el promedio de territorio común se multiplica por el peso de los costes salariales en el gasto medio autonómico $(39,3 \%)$. 
La cifra resultante es la corrección parcial por diferencias en niveles de precios que se aplica a la población ajustada de cada región para obtener una población ajustada corregida provisional. Finalmente, esta magnitud provisional se ajusta en la misma proporción en todas las regiones de forma que su suma sea igual a la población original (ajustada y real) del conjunto de las comunidades de régimen común. La última columna muestra la variación porcentual generada por la corrección por niveles de precios en la población ajustada regional o, lo que es lo mismo, en las necesidades totales de gasto.

Una vez corregida la población ajustada, podemos calcular el indicador habitual de necesidades de gasto por habitante y ver cómo ha variado con la corrección por precios. Los resultados se resumen en el Gráfico 7. Si nos atenemos a la propuesta de síntesis de Costa et al (2015), a la que los autores atribuyen una mayor fiabilidad, las correcciones más importantes son las que afectan a Madrid y Cataluña, al alza, y a Extremadura, Canarias y Castilla la Mancha, a la baja.

\section{Gráfico 7: Efectos sobre las necesidades de gasto total por habitante en 2013 de introducir una corrección parcial por niveles de precios con estimaciones alternativas del índice de precios relativos regionales de Costa et al (2015)}

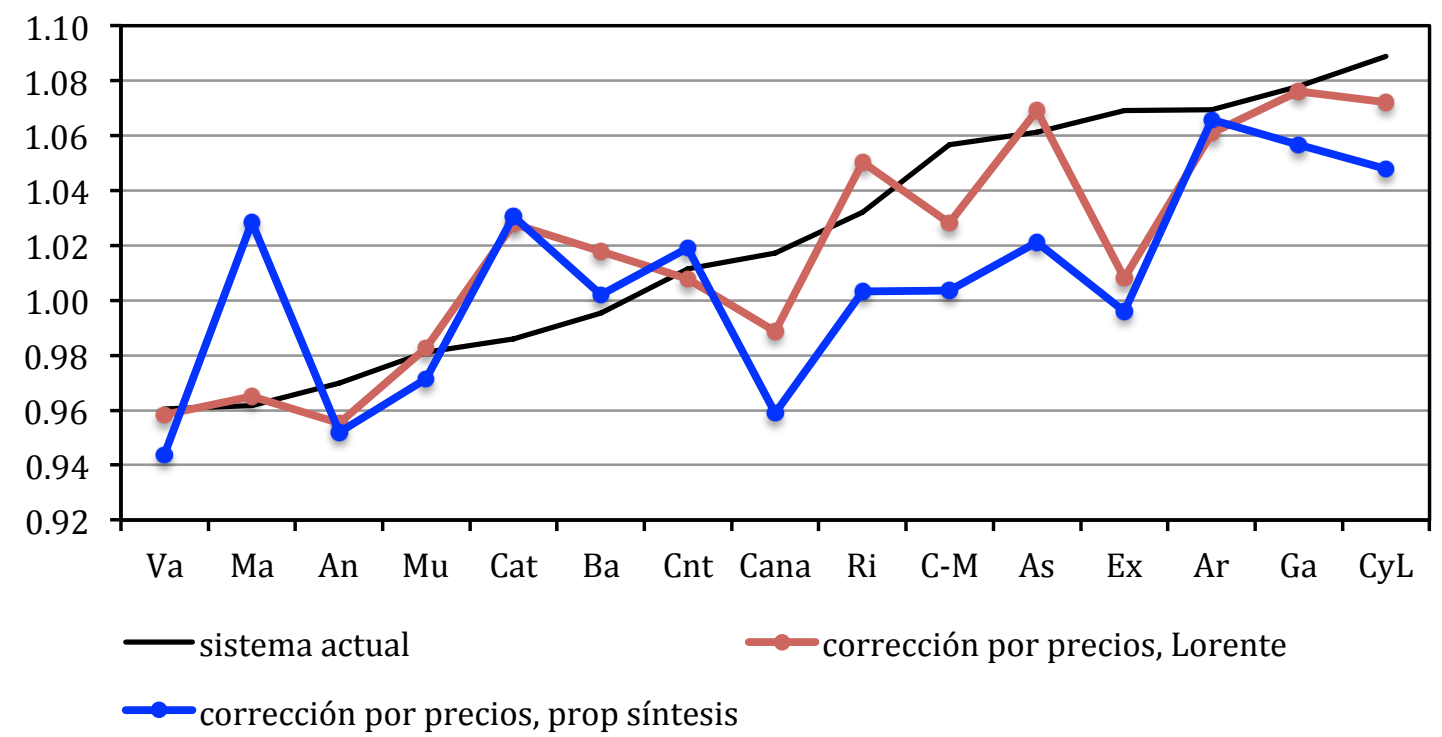

\section{2. ¿Corrección por niveles de renta?}

Parece razonable esperar que la presión sobre los principales servicios públicos se reduzca según aumente el nivel de renta entre regiones debido al trasvase de usuarios hacia servicios privados. En este apartado se realiza un análisis preliminar de esta cuestión que tiende a confirmar esta hipótesis y sirve de base para una cuantificación, necesariamente muy tentativa, de la incidencia de este fenómeno sobre el gasto autonómico.

Consideremos en primer lugar el caso de la educación no universitaria. El Ministerio de Educación (MECyD, 2015c) ofrece datos de alumnado por niveles y tipo de centro de los que he extraído los matriculados en centros presenciales de primeria, secundaria y FP, distinguiendo entre los que asisten a centros públicos, a centros privados concertados y a centros privados "puros." Seguidamente, he construido un indicador de las necesidades relativas de gasto 
público educativo de cada región ponderando a cada uno de estos tipos de estudiantes de acuerdo con su coste para el sector público. En particular, he asignado un coste de 0 a los estudiantes de centros privados puros, de 1 a los matriculados en centros públicos y de 0,573 a los que estudian en centros privados concertados. Esta última cifra refleja el coste medio estimado para el sector público de una plaza concertada en educación secundaria, expresado como fracción del coste directo de una plaza pública al mismo nivel, calculado con datos agregados nacionales de 2010 por de la Fuente y Boscá (2014, p. 7).

Gráfico 8: Necesidades de gasto público educativo por estudiante vs. renta per capita, 2012 promedio régimen común $=100$

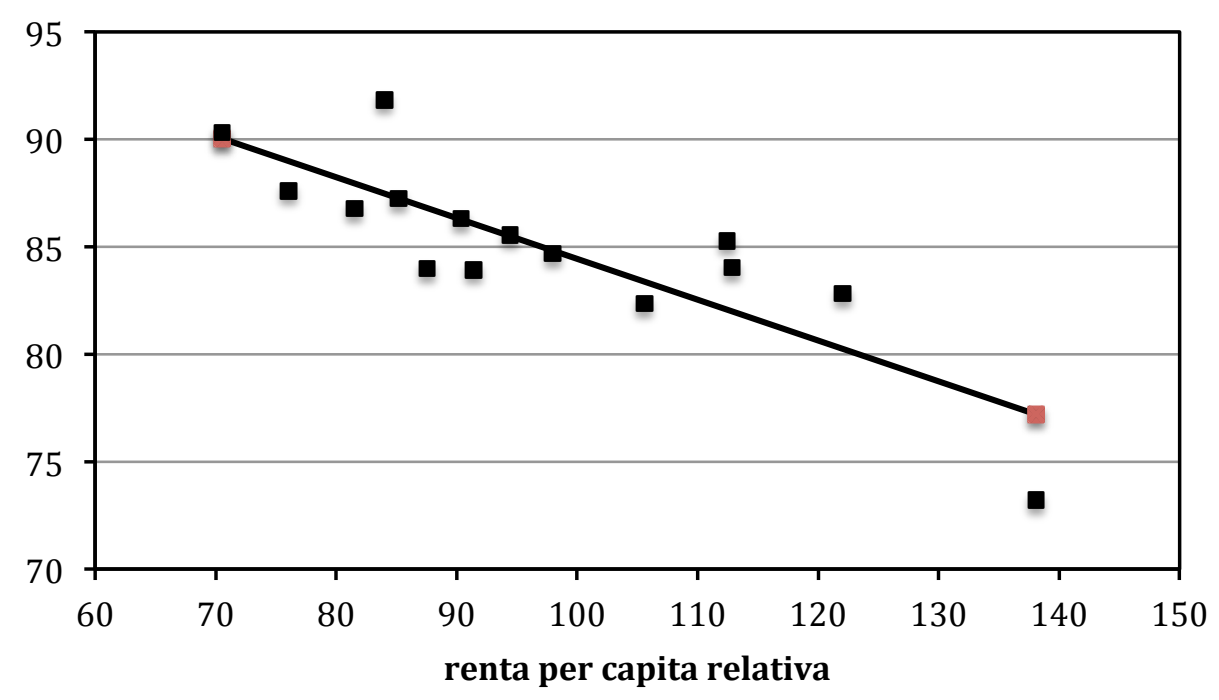

Gráfico 9: Necesidades de gasto público educativo por usuario potencial (pob. 6-17) vs. renta per capita, 2012

promedio régimen común $=100$

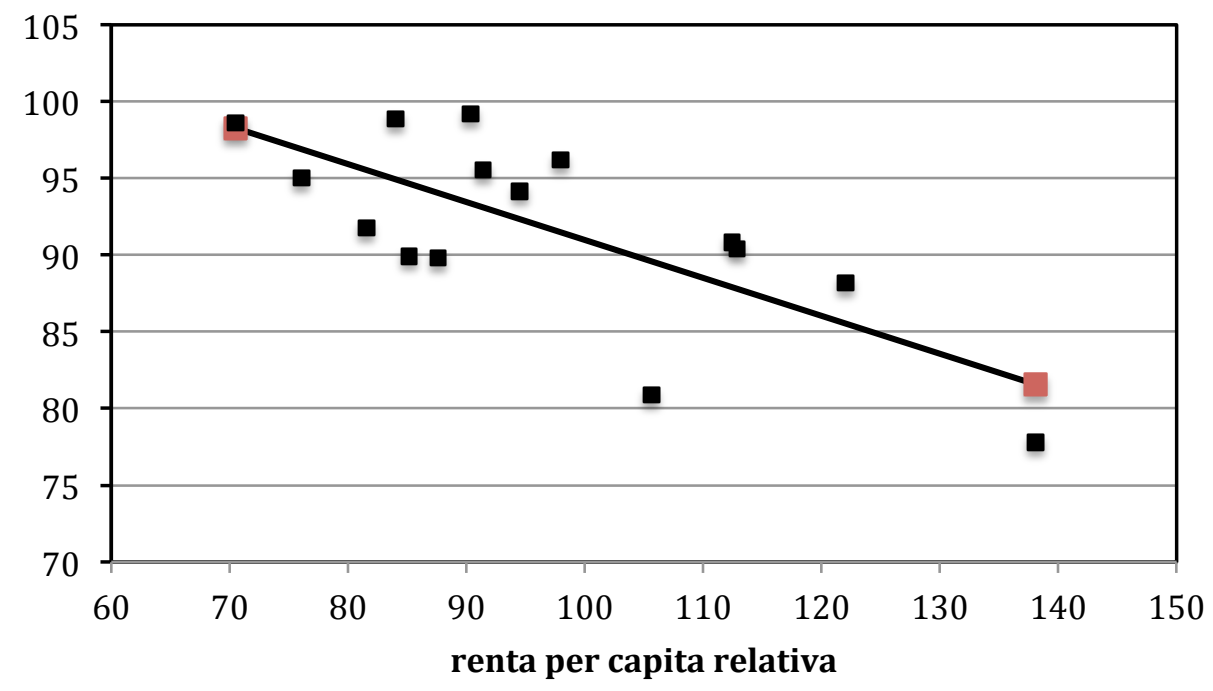

Dividiendo este indicador de usuarios ponderados por coste o de necesidades de gasto totales por el número total de estudiantes obtenemos un indicador de necesidades relativas de gasto público por usuario (estudiante). Si tomamos como denominador la población en edad escolar en vez de la población estudiantil matriculada, tenemos un indicador de necesidades de gasto 
por usuario potencial. Los Gráficos 8 y 9 muestran que existe una clara relación negativa entre cada uno de estos indicadores y la renta per cápita, trabajando siempre con variables normalizadas de forma que su media sea 100 en la muestra integrada por las comunidades autónomas de régimen común.

Cuadro 16: relación estimada entre necesidades de gasto educativo por estudiante o estudiante potencial y renta per cápita

\begin{tabular}{lccc}
\hline necesidades de gasto por & constante & pendiente & $R^{2}$ \\
estudiante & 103,4 & $-0,190$ & 0,700 \\
& $(30,5)$ & $(5,51)$ & \\
población 6-17 & 115,7 & -0.247 & 0,534 \\
& $(18,41)$ & $(3,84)$ & \\
\hline
\end{tabular}

Algo similar sucede con la sanidad. En este caso, he utilizado datos de la Encuesta Nacional de Salud 2011-12 (MSSSI, 2015) sobre el tipo de cobertura sanitaria de la que disfruta la población (privada, pública, ambas o ninguna) para construir un indicador de usuarios ponderados por coste de la misma forma que se ha hecho más arriba. En este caso, sin embargo, no se dispone de información sobre el coste relativo para el sector público de los usuarios con doble cobertura, por lo que a este grupo se le ha asignado a ojo una ponderación de 0,30 , mientras que a los que sólo tienen cobertura pública se les asigna una ponderación de 1 y a los que sólo la tienen privada un peso de 0 . En este caso, la ecuación estimada es de la forma:

Nec. de gasto por usuario potencial $=109,6-0,187$ * ypc $R^{2}=0,535$

(t) $\quad(4,75) \quad(3,87)$

con un coeficiente de pendiente de -0,19 que es aproximadamente consistente con la estimación algo más cuidadosa que se ofrece en de la Fuente y Gundín (2009, Cuadro 9).

Gráfico 10: Necesidades de gasto público sanitario por usuario potencial (población total) vs. renta per capita, 2012

promedio régimen común $=100$

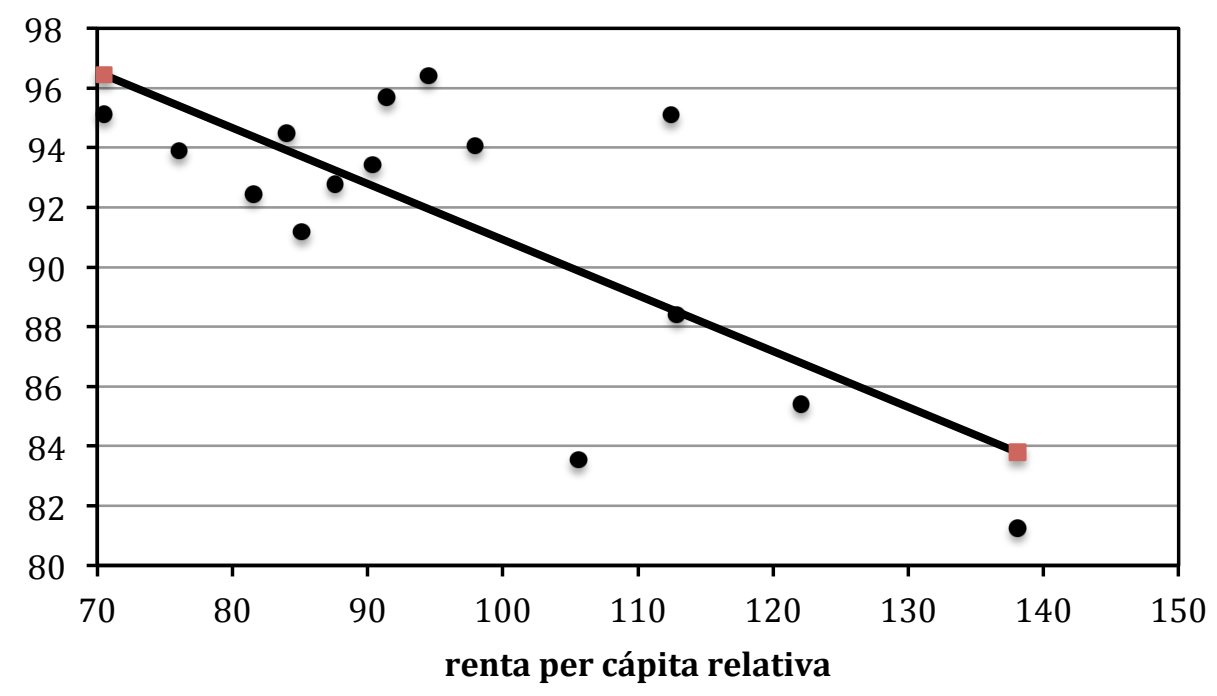


Cuadro 17: Cálculo del coeficiente que recoge el impacto de la renta per capita vía sanidad y educación

\begin{tabular}{lccc}
\hline & coeficiente & peso en gasto & coef ponderado \\
sanidad & $-0,1872$ & 0,4801 & $-0,0899$ \\
educación & $-0,1900$ & 0,2594 & $-0,0493$ \\
total & & & $\mathbf{- 0 , 1 3 9 2}$ \\
\hline
\end{tabular}

Combinando los resultados anteriores podemos aproximar la corrección por renta per cápita relativa que habría que aplicar a las necesidades regionales de gasto sanitario y educativo. ${ }^{8}$ En primer lugar, se calcula una media ponderada de los coeficientes de pendiente de las regresiones pertinentes, tal como se detalla en el Cuadro 17.

Cuadro 18: Cálculo de la corrección total por renta per cápita a la población ajustada (teniendo en cuenta los efectos vía sanidad y educación)

\begin{tabular}{lccrrrr} 
& $\begin{array}{c}\text { Renta per } \\
\text { capita } \\
\text { relativa }\end{array}$ & $\begin{array}{c}\% \\
\text { corrección }\end{array}$ & $\begin{array}{c}\text { Ajustada } \\
\text { original }\end{array}$ & $\begin{array}{c}\text { Pob. Ajust } \\
\text { corregida } \\
\text { preliminar }\end{array}$ & $\begin{array}{c}\text { Pob. Ajust } \\
\text { corregida } \\
\text { final }\end{array}$ & $\begin{array}{c}\text { var \% pob } \\
\text { ajustada }\end{array}$ \\
Extremadura & 70,5 & $+4,10 \%$ & 1.180 .337 & 1.228 .783 & 1.228 .670 & $+4,10 \%$ \\
Andalucia & 76,0 & $+3,34 \%$ & 8.185 .501 & 8.458 .601 & 8.457 .819 & $+3,34 \%$ \\
Murcia & 81,5 & $+2,57 \%$ & 1.444 .162 & 1.481 .279 & 1.481 .142 & $+2,57 \%$ \\
C.-La Mancha & 84,0 & $+2,22 \%$ & 2.220 .075 & 2.269 .442 & 2.269 .232 & $+2,22 \%$ \\
Canarias & 85,1 & $+2,07 \%$ & 2.155 .082 & 2.199 .626 & 2.199 .422 & $+2,07 \%$ \\
Valencia & 87,6 & $+1,73 \%$ & 4.910 .946 & 4.995 .944 & 4.995 .482 & $+1,73 \%$ \\
Galicia & 90,4 & $+1,34 \%$ & 2.981 .328 & 3.021 .270 & 3.020 .990 & $+1,34 \%$ \\
Asturias & 91,4 & $+1,19 \%$ & 1.133 .620 & 1.147 .158 & 1.147 .052 & $+1,19 \%$ \\
Cantabria & 94,5 & $+0,77 \%$ & 598.634 & 603.240 & 603.184 & $+0,77 \%$ \\
Cast. YLeón & 98,0 & $+0,28 \%$ & 2.743 .355 & 2.751 .123 & 2.750 .868 & $+0,28 \%$ \\
Baleares & 105,6 & $-0,78 \%$ & 1.106 .547 & 1.097 .927 & 1.097 .826 & $-0,78 \%$ \\
La Rioja & 112,4 & $-1,73 \%$ & 332.334 & 326.585 & 326.555 & $-1,73 \%$ \\
Aragón & 112,8 & $-1,79 \%$ & 1.440 .627 & 1.414 .886 & 1.414 .756 & $-1,79 \%$ \\
Cataluña & 122,0 & $-3,07 \%$ & 7.446 .814 & 7.218 .567 & 7.217 .900 & $-3,07 \%$ \\
Madrid & 138,1 & $-5,30 \%$ & 6.246 .404 & 5.915 .414 & 5.914 .867 & $-5,30 \%$ \\
total & 100,0 & & 44.125 .765 & 44.129 .846 & 44.125 .765 & $0,00 \%$ \\
\hline
\end{tabular}

Seguidamente, en el Cuadro 18 se calcula la corrección a la población ajustada total, ignorando posibles efectos sobre otras partidas de gasto que en algunos casos (como el de la dependencia) también podrían ser significativos. El coeficiente medio calculado en el Cuadro 17 se multiplica seguidamente por la desviación porcentual de la renta per cápita regional sobre la media nacional para obtener la corrección porcentual que se aplica en primera instancia a la población ajustada regional, obteniendo así una población ajustada corregida preliminar. Puesto que la suma de las poblaciones corregidas preliminares no coincide exactamente con el dato original de población (ajustada y real), finalmente el dato preliminar se reajusta en la misma proporción en todas las regiones de forma que su suma vuelva a ser igual a la población total original. Por

\footnotetext{
${ }^{8}$ Una forma alternativa de proceder sería utilizar indicadores de población demandante ponderados por costes como los construidos más arriba. Estos indicadores se utilizarían directamente para calcular las necesidades de gasto educativo y sanitario en vez de introducir a posteriori una corrección indirecta ligada al nivel de renta. Un posible problema con esta forma de proceder es que la financiación regional podría terminar dependiendo de indicadores potencialmente manipulables por las administraciones regionales.
} 
último, se calcula el indicador habitual de necesidades totales de gasto por habitante así como su variación en relación con la situación actual, que se muestra en el Gráfico 11.

Gráfico 11: Efectos sobre las necesidades de gasto total por habitante en 2013 de introducir una corrección por niveles de renta

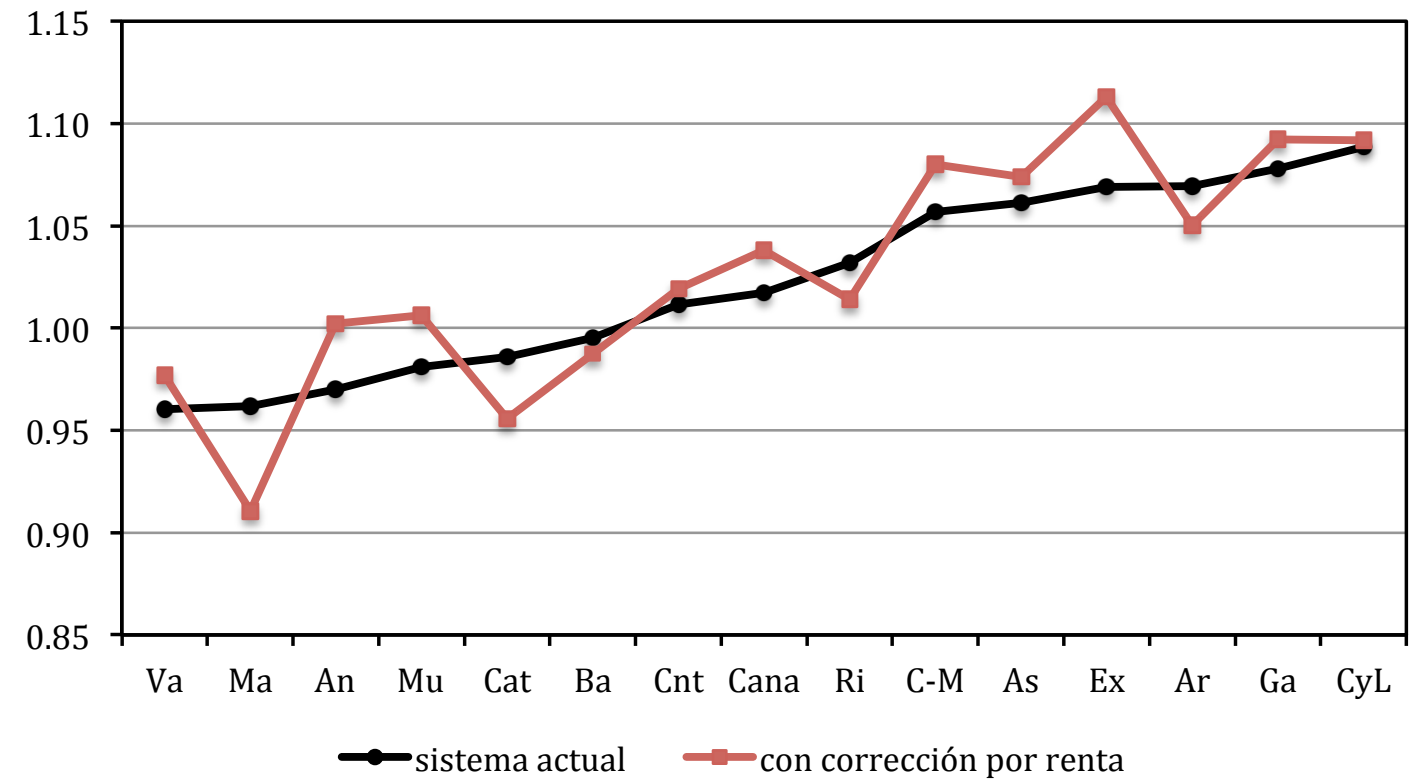

Gráfico 12: Variación porcentual de las necesidades de gasto total por habitante en 2013 Inducida por la introducción de correcciones por niveles de renta y precios (método de síntesis) y efecto neto de ambas correcciones

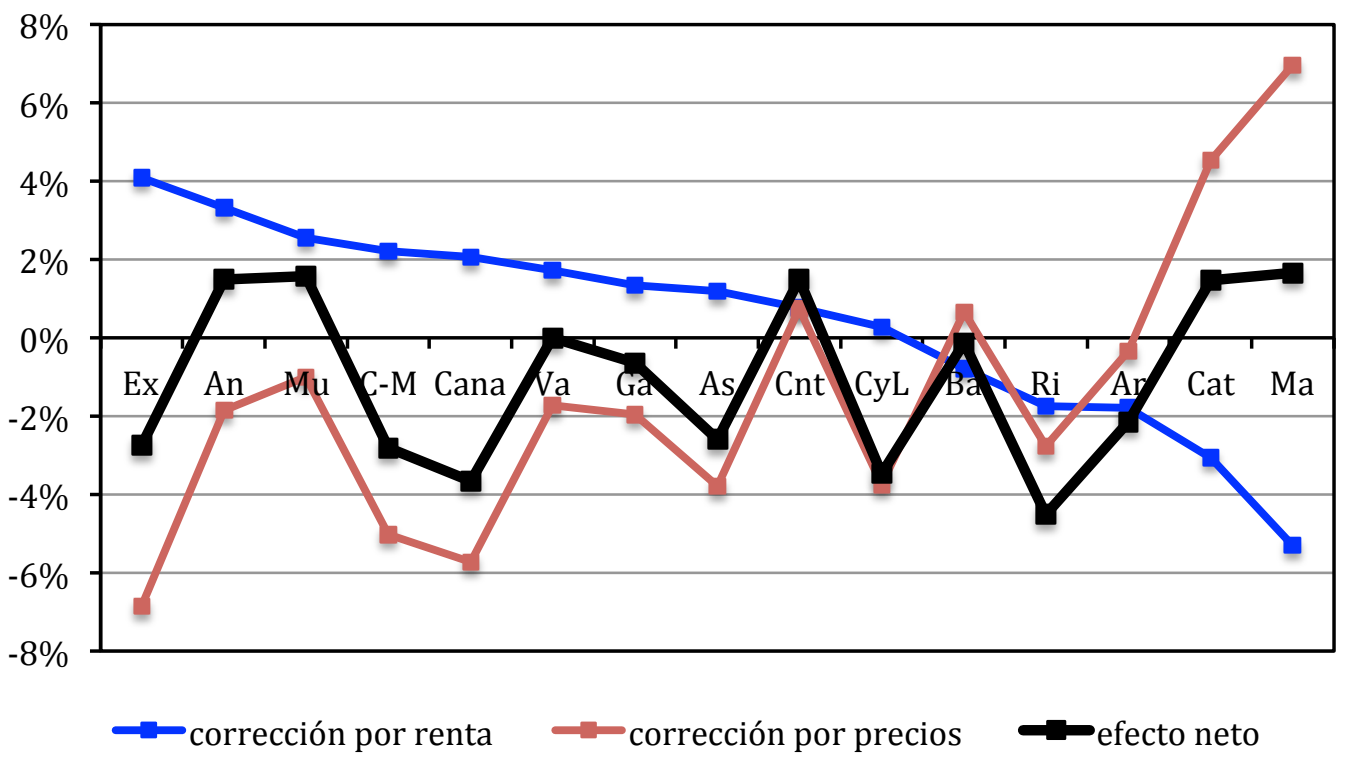

Finalmente, el Gráfico 12 muestra las variaciones en las necesidades de gasto por habitante generadas conjuntamente por las correcciones por niveles de renta y de precios (utilizando el índice de síntesis propuesto por Costa et al), con las regiones ordenadas a lo largo del eje horizontal de acuerdo con su nivel de renta per cápita. Las dos correcciones tienden a compensarse en la mayor parte de las regiones, dejando efectos netos generalmente inferiores a los dos puntos porcentuales. Las principales excepciones son la Rioja, Castilla y León, 
Extremadura, Castilla la Mancha, Canarias Aragón y Asturias, que verían reducidas en más de dos puntos sus necesidades de gasto por habitante con la introducción simultánea de ambas correcciones.

\section{Una propuesta de reforma y análisis de sus implicaciones}

En apartados anteriores de este trabajo se han discutido algunas posibles modificaciones de la fórmula de necesidades de gasto del sistema de financiación regional y cuantificado los efectos que tendría adoptar cada una de ellas por separado, partiendo de la situación actual. En esta sección final se avanza una propuesta específica de modificación inmediata de la fórmula, que incorpora buena parte de las sugerencias discutidas más arriba pero no todas ellas, y se cuantifican sus efectos.

El Cuadro 19 resume la nueva formula propuesta para el cálculo de las necesidades de gasto y la compara con la actual. Cotejando las dos columnas, vemos que las principales novedades son la introducción de una partida de costes fijos y de la población en riesgo de pobreza o exclusión, el cambio en las ponderaciones de las variables poblacionales que resulta de ligar éstas al patrón observado de gasto y el desdoblamiento de la variable de necesidades educativas, con el número de estudiantes universitarios y la población 3-18 sustituyendo a la población 0-16. Por lo demás, se mantienen las ponderaciones actuales de los indicadores geográficos y no se contempla todavía la introducción de posibles correcciones por niveles de precios y de renta o de alguna nueva variable de reparto ligada al flujo o al stock de población inmigrante. Aunque estas tres últimas propuestas tienen, a mi entender, considerable mérito, habría que madurarlas bastante más antes de incorporarlas al sistema.

Cuadro 19: Resumen de la propuesta de modificación de la fórmula de necesidades de gasto

\begin{tabular}{lrr}
\hline Indicador: & $\begin{array}{c}\text { Sistema } \\
\text { actual }\end{array}$ & Propuesta \\
- población protegida equivalente & $38 \%$ & $47,79 \%$ \\
- población empadronada a 1 de enero & $30 \%$ & $15,32 \%$ \\
- población 0-16 & $20,5 \%$ & 0 \\
- población 3-18 & 0 & $20,70 \%$ \\
- universitarios matriculados en centros públicos (grado y master) & 0 & $5,14 \%$ \\
- población 65+ & $8,5 \%$ & $4,71 \%$ \\
- población en riesgo de pobreza o exclusión & 0 & $2,35 \%$ \\
- partida para costes fijos & 0 & $1 \%$ \\
- superficie & $1,8 \%$ & $1,8 \%$ \\
- dispersión de la población (entidades singulares) & $0,6 \%$ & $0,6 \%$ \\
- insularidad & $0,6 \%$ & $0,6 \%$
\end{tabular}

Las implicaciones de la modificación propuesta de la fórmula de necesidades de gasto se ilustran en los Gráficos 13 y 14 y en el Cuadro 20. Como cabría esperar en base a la discusión previa, las regiones más beneficiadas por el cambio serían las comunidades autónomas más pequeñas, especialmente la Rioja y Cantabria, cuyas necesidades de gasto por habitante se incrementarían en un 5,6 y un 2,7 por ciento respectivamente. Seguidamente vendría 
Extremadura $(+2,4 \%)$ y, en el extremo opuesto, Cataluña $(-2,2 \%)$. Para el resto de las comunidades, los cambios serían reducidos, situándose en la mayor parte de los casos por debajo de un punto y medio porcentual al alza o a la baja. En consecuencia, la utilización de la nueva fórmula propuesta para calcular la población ajustada no cambiaría apreciablemente la distribución de la financiación por habitante ajustado que observamos con datos de 2013, aunque reduciría en alguna medida la sobrefinanciación aparente de las comunidades situadas en la cola superior de la distribución al corregir al alza las necesidades de gasto de casi todas ellas, y muy especialmente las de las comunidades más pequeñas.

Gráfico 13: Efecto sobre las necesidades de gasto por habitante en 2013 de la propuesta de modificación de la fórmula de reparto

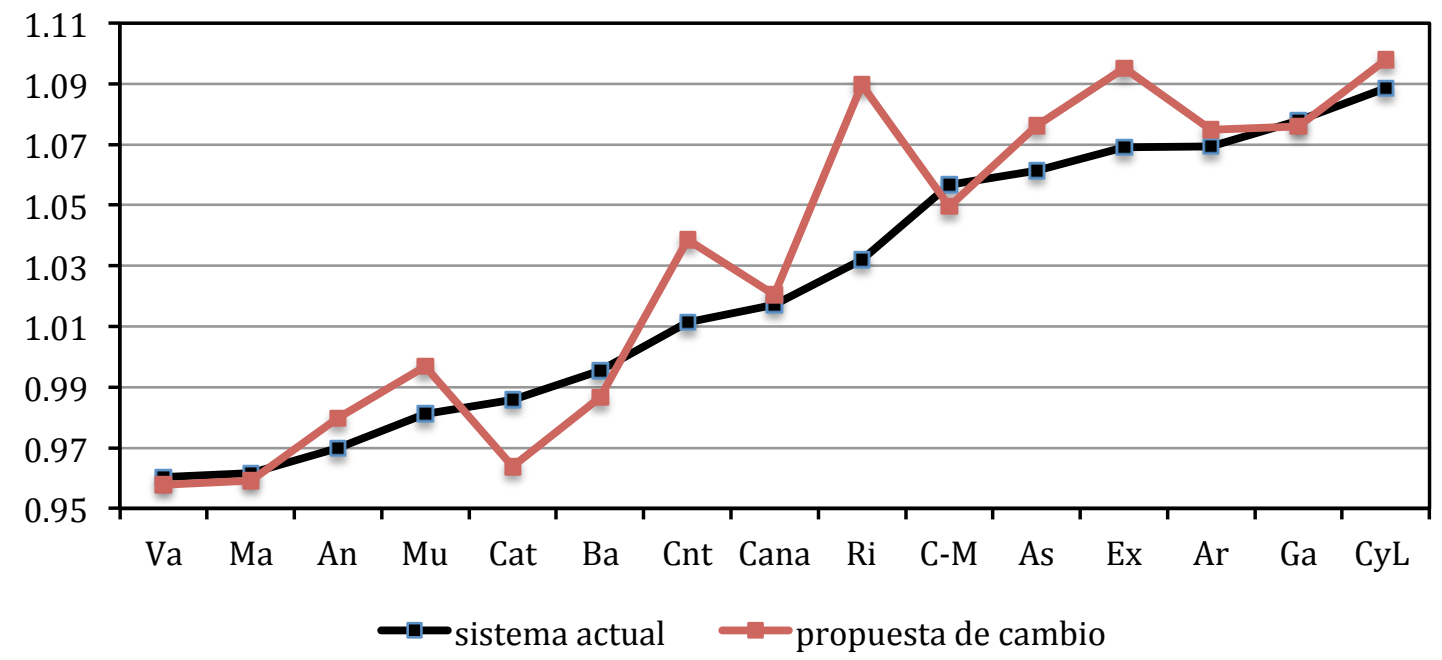

Cuadro 20: Efecto sobre las necesidades de gasto por habitante en 2013 de la propuesta de modificación de la fórmula de reparto

\begin{tabular}{lccc}
\hline \multicolumn{3}{c}{ Con } \\
Rioja & $\begin{array}{c}\text { Ngph con } \\
\text { sistema actual }\end{array}$ & $\begin{array}{c}\text { propuesta de } \\
\text { cambio }\end{array}$ & $\%$ var \\
Cantabria & 1,032 & 1,090 & $5,60 \%$ \\
Extremadura & 1,011 & 1,038 & $2,68 \%$ \\
Murcia & 1,069 & 1,095 & $2,43 \%$ \\
Asturias & 0,981 & 0,997 & $1,60 \%$ \\
Andalucía & 1,061 & 1,076 & $1,41 \%$ \\
Cast y León & 0,970 & 0,980 & $1,04 \%$ \\
Aragón & 1,089 & 1,098 & $0,85 \%$ \\
Canarias & 1,069 & 1,075 & $0,50 \%$ \\
Galicia & 1,017 & 1,020 & $0,32 \%$ \\
Madrid & 1,078 & 1,076 & $-0,18 \%$ \\
Valencia & 0,962 & 0,959 & $-0,25 \%$ \\
Cast. La Mancha & 0,960 & 0,958 & $-0,26 \%$ \\
Baleares & 1,057 & 1,049 & $-0,68 \%$ \\
Cataluña & 0,995 & 0,987 & $-0,87 \%$ \\
\hline
\end{tabular}


Gráfico 14: Financiación efectiva por habitante ajustado en 2013 con población ajustada del sistema actual y bajo la propuesta de reforma

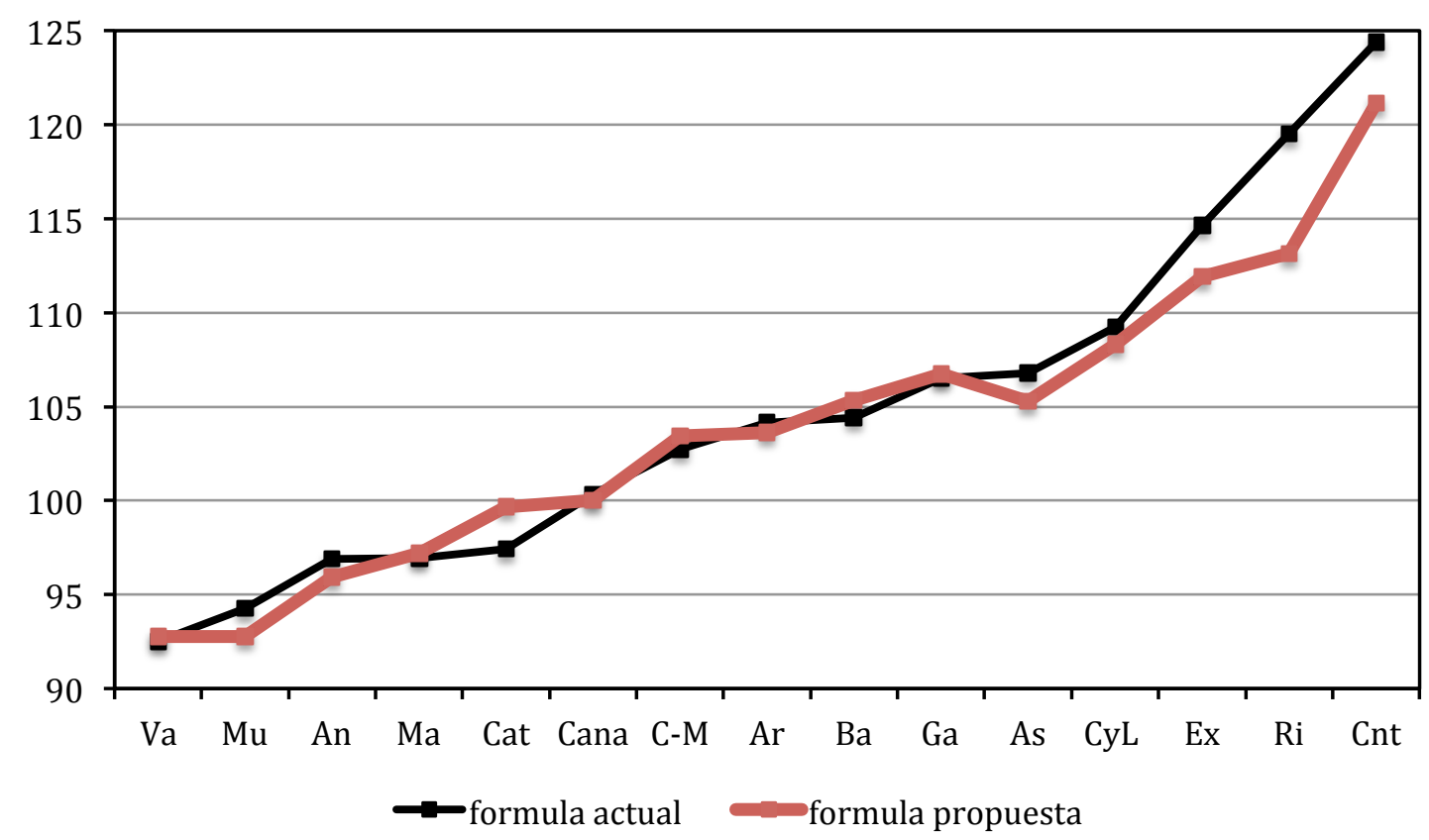

Anexo: Detalle de la financiación condicionada de las Comunidades Autónomas

\section{a) Competencias singulares financiadas a través del Fdo. de Suficiencia}

\section{partida}

CS01: Profesores de religión

CS02: Hospitales provinciales asumidos por ccaa

CS03: ISM sanidad

CS04: Administración de Justicia

CS05: Instituciones Penitenciarias, Cataluña

CS06: "Normalización" lingüística

CS07: Obras hidráulicas

CS08: Policía áutonómica catalana y tráfico

CS09/1: ISM 2007 por PGE, sanidad

CS09/2: ISM 2007 por PGE, serv. sociales

CS10: Infraestructuras REF Canarias

CS11: Transporte interinsular Canarias

CS12: Participación provincial en ingresos del Estado

CS13: Confederaciones hidrográficas, Andalucía

CS14: ISM educación y servicios sociales

CS15: Formación continua

CS16: Parques Nacionales

CS17: Autorizaciones iniciales trabajo

CS18: Inspección de trabajo

total

\author{
gasto clasificada como \\ 135 3b. educación \\ 353 3a. sanidad \\ 29 3a. sanidad \\ 1,051 1a justicia \\ 358 1a justicia \\ 136 3d. cultura \\ 160 4. actuaciones económicas \\ 1,108 1a justicia \\ 66 3a. sanidad \\ 8 2a. servicios y promoción social \\ 95 4. actuaciones económicas \\ 25 4. actuaciones económicas \\ No es financiación condicionada \\ 156 4. actuaciones económicas \\ 26 2a. servicios y promoción social \\ $102 \mathrm{~b}$. fomento del empleo \\ 604 . actuaciones económicas \\ 3 2d. otros \\ 12 2d. otros
}


b) Detalle de transferencias de la liquidación de ingresos de las CCAA

\author{
Transferencias corrientes de la UE \\ - Del Fondo Social Europeo \\ - Del FEDER \\ Fondos de la PAC \\ de otros fondos \\ subtotal
}

Transferencias de capital de otras

administraciones

FCI

Fondo complementario

del FSE

del FEDER

del Feoga orientación

del F de Cohesión

del IFEP

de otros fondos

fondos de la PAC (parte no excluida a priori)

subtotal

\section{c) Convenios y subvenciones gestionadas}

servicios sociales y promoción social

fomento del empleo

vivienda

gestión y administración de la seguridad social

sanidad

educación

cultura

agricultura, pesca y alimentación

subvenciones al transporte

infraestructuras

$\mathrm{I}+\mathrm{D}$

servicios de caracter general

total
$2972 b$. fomento del empleo

4 4. actuaciones económicas

29 4. actuaciones económicas

6 4. actuaciones económicas 336

529 4. actuaciones económicas

185 4. actuaciones económicas

121 2b. fomento del empleo

1,615 4. actuaciones económicas

12 4. actuaciones económicas

99 4. actuaciones económicas

138 4. actuaciones económicas

143 4. actuaciones económicas

817 4. actuaciones económicas

3,658

Nota: Desglose por niveles de la financiación específica para la educación

De acuerdo con MHAP (2015c) el grueso de la financiación condicionada asignada a educación corresponde a la educación no universitaria. Las únicas excepciones son una partida de 8,7 millones asignada a enseñanzas universitarias y otra de 1,8 millones para la promoción del deporte escolar y universitario. En este último caso, he supuesto que un $25 \%$ corresponde a las universidades. 


\section{Referencias}

Boletín Oficial del Estado (BOE, 2009). Ley 22/2009, de 18 de diciembre, por la que se regula el sistema de financiación de las Comunidades Autónomas de régimen común y ciudades con estatuto de autonomía y se modifican determinadas normas tributarias. (B.O.E. núm. 305 de 19/12/2009).

http: / / www.boe.es/boe/dias / 2009/12/19/pdfs / BOE-A-2009-20375.pdf

Costa, A., J. García, X. López y J. L. Raymond (2015). “Estimació de les paritats de poder adquisitiu per a les comunitats autònomes españoles." Generalitat de Catalunya, Departament d'Economia y Coneixement, Monografies, no. 17 / 2015.

de la Fuente, A. (2010). "El nuevo sistema de financiación regional: un análisis crítico y proyecciones para 2009." Hacienda Pública Española/Revista de Economía Pública 195(4), pp. 91138.

de la Fuente, A. (2015). “La evolución de la financiación de las comunidades autónomas de régimen común, 2002-2013." FEDEA, Estudios sobre la Economia Española, no. 2015/19. http:/ / www.fedea.net/ documentos-hacienda-autonomica/

de la Fuente, A. y J. E. Boscá (2014). “Gasto educativo por regiones y niveles en 2010." Mimeo, Instituto de Análisis Económico CSIC, Barcelona. https: / / ideas.repec.org/p/aub/autbar/944.14.html

de la Fuente, A. y X. Vives (2003). Políticas públicas y equilibrio territorial en el Estado autonómico. Fundación BBVA e Institut d'Estudis Autonòmics de la Generalitat de Catalunya, Bilbao.

de la Fuente, A. y M. Gundín (2008a). La financiación regional en España y en cuatro países federales. Fundación Caixa Galicia, Santiago de Compostela.

de la Fuente. A y M. Gundín (2008b). "El sistema de financiación de las comunidades autónomas de régimen común: un análisis crítico y algunas propuestas de reforma." Investigaciones Regionales 13, pp. 213-62.

de la Fuente, A. y M. Gundín (2009). "Sobre el reparto de la financiación sanitaria." Investigaciones Económicas XXXIII(3), pp. 473-527. http: / / ideas.repec.org/a/iec/inveco/v33y2009i3p473-527.html

Grupo de trabajo de análisis del gasto sanitario (GTS, 2007). Informe del Grupo de Trabajo de análisis del gasto sanitario. 2007. Ministerio de Sanidad y Consumo, Madrid. http:/ / www.msc.es/estadEstudios / estadisticas / sisInfSanSNS / finGastoSanit.htm

http:// documentos.fedea.net/pubs/eee/ eee2014-03.pdf

Instituto de Estudios Turísticos (IET, 2013a). EGATUR, Encuesta de Gasto Turístico, 2012. http: / / www.iet.tourspain.es/es-es/estadisticas/egatur/paginas / default.aspx

Instituto de Estudios Turísticos (IET, 2013b). Movimientos turísticos de los españoles, FAMILITUR. Año 2012. http: / / www.iet.tourspain.es / es-es / estadisticas / familitur/paginas / default.aspx

Instituto Nacional de Estadística (INE, 2015a). Estadística del padrón continuo. Población de las CCAA por edad. http: / / www.ine.es $/$ jaxi $/$ menu.do?type $=$ pcaxis $\&$ path $=\% 2 F t 20 \% 2 F e 245 \&$ file $=$ inebase $\& \mathrm{~L}=0$

Instituto Nacional de Estadística (INE, 2015b). Estadística de condiciones de vida. Riesgo de pobreza o exclusión social. http: / / www.ine.es / dynt3/inebase/es / index.htm?padre=1928\&capsel=1930 
Intervención General de la Administración del Estado (IGAE, 2015). Contabilidad Nacional. Clasificación funcional del gasto del subsector Administración Regional (COFOG). http:/ / www.igae.pap.minhap.gob.es/sitios/igae/esES/ContabilidadNacional/infadmPublicas/infadmcomunidadesautonomas/Paginas/iacof og.aspx

López Laborda, J. y F. Rodrigo (2000). "La cuantificación de las necesidades de gasto de las Comunidades Autónomas. Descripción y valoración de la experiencia comparada y de la investigación aplicada." Instituto de Estudios Fiscales, Serie Investigaciones. Madrid.

Lorente, J. R. (1992). "La Dispersión Geográfica de los Salarios." Sintesis Mensual de Indicadores Económicos, Ministerio de Economía y Hacienda, Madrid.

Ministerio de Educación, Cultura y Deporte (MECyD, 2015a). Estadística de Estudiantes Universitarios. Curso 2012/2013.

http: / / www.mecd.gob.es/educacion-mecd/areas-educacion/ universidades/ estadisticasinformes/estadisticas/alumnado/2012-2013.html

Ministerio de Educación, Cultura y Deporte (MECyD, 2015b). Estadística del gasto público en educación. Año 2012.

http: / / www.mecd.gob.es/ servicios-al-ciudadano-mecd/estadisticas / educacion/ recursoseconomicos/gasto-publico/2012.html

Ministerio de Educación, Cultura y Deporte (MECyD, 2015c). Enseñanzas no universitarias. Alumnnado matriculado. Curso 2012-2013.

http: / / www.mecd.gob.es/ servicios-al-ciudadano-mecd / estadisticas / educacion/nouniversitaria/alumnado/matriculado/2012-2013-Ultimos-RD.html

Ministerio de Hacienda y Administraciones Públicas (MHAP, 2015a). Liquidación de los presupuestos de las comunidades autónomas. Secretaría General de Coordinación Autonómica y Local, Madrid. http://serviciosweb.meh.es/apps/publicacionliquidacion/aspx/menuInicio.aspx

Ministerio de Hacienda y Administraciones Públicas (MHAP, 2015b). Sistema de Cuentas Públicas Territorializadas. Año 2012.

http: / / www.minhap.gob.es/es-ES/CDI / Paginas/Sistema-cuentas-territorializadas2012.aspx

Ministerio de Hacienda y Administraciones Públicas (MHAP, 2015c). Las Haciendas Autonómicas en Cifras, 2012.

http://www.minhap.gob.es/es-

ES/Areas\%20Tematicas/Financiacion\%20Autonomica/Paginas/haciendas\% 202005.aspx

Ministerio de Sanidad, Servicios Sociales e Igualdad (MSSSI, 2015). Encuesta Nacional de Salud de España 2011/12. Tabla 2.183. Modalidad de cobertura sanitaria http: / / www.msssi.gob.es/estadEstudios/estadisticas/encuestaNacional/encuestaNac2011 / encuestaResDetall2011.htm

Murillo, C. y otros (1992). "Coste de la Insularidad en Canarias." Gobierno de Canarias, Consejería de Economía y Hacienda.

Universitat de les Illes Balears (UIB, 2014). “Estimación de los costes de insularidad de les Illes Balears." Mimeo, Palma de Mallorca. 